\title{
ABSTRACT \\ LONGITUDINAL LINKS AMONG MOTHER AND CHILD EMOTION REGULATION, MATERNAL EMOTION SOCIALIZATION, AND CHILD ANXIETY
}

\author{
by Natalee Naomi Price
}

Child anxiety is highly prevalent, with many typically-developing children showing patterns of excessive worry. These anxiety symptoms often emerge in toddlerhood and are highly predictive of children's later anxiety outcomes, underscoring the importance of early mechanisms (e.g., emotion processes) and contexts (e.g., family environment) involved in anxiety symptoms arising in early childhood. Still, there remains a need for integrative, longitudinal, and multimethod models of family emotion processes that may contribute to child anxiety. The current study examined how mothers' emotion dysregulation related to their emotion socialization practices (either supportive or unsupportive) and children's emotion regulation (either attentionor caregiver-focused) over time, with a primary focus on how these emotion processes are relevant to later child anxiety. Results indicated that models tended to fit the data well. Maternal emotion dysregulation consistently predicted child anxiety, and to a lesser extent, relations emerged among emotion processes. Serial mediation was not significant; however, there was one marginally significant indirect effect. Specifically, greater maternal emotion dysregulation predicted greater unsupportive emotion socialization, which in turn related to children's greater caregiver-focused emotion regulation. These findings lend partial support to current theoretical models of family emotion processes and child anxiety development and suggest promising avenues of future research. 
LONGITUDINAL LINKS AMONG MOTHER AND CHILD EMOTION REGULATION, MATERNAL EMOTION SOCIALIZATION, AND CHILD ANXIETY

\author{
Thesis \\ Submitted to the \\ Faculty of Miami University \\ in partial fulfillment of \\ the requirements for the degree of \\ Master of Arts \\ by \\ Natalee Naomi Price \\ Miami University \\ Oxford, Ohio \\ 2019 \\ Advisor: Elizabeth J. Kiel, Ph.D \\ Reader: Aaron M. Luebbe, Ph.D \\ Reader: Jennifer H. Green, Ph.D
}

C2019 Natalee Naomi Price 
This thesis titled

\section{LONGITUDINAL LINKS AMONG MOTHER AND CHILD EMOTION REGULATION, MATERNAL EMOTION SOCIALIZATION, AND CHILD ANXIETY}

$$
\text { by }
$$

Natalee Naomi Price

has been approved for publication by

The College of Arts and Sciences

and

Department of Psychology

Elizabeth J. Kiel, Ph.D

Aaron M. Luebbe, Ph.D

Jennifer H. Green, Ph.D 


\section{Table of Contents}

List of Tables .................................................................................................................... iv

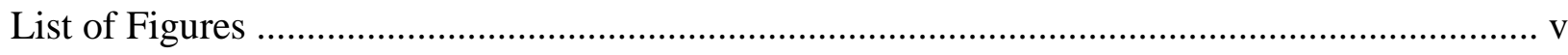

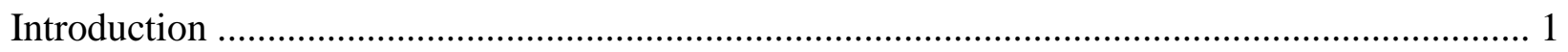

Parent Characteristics Salient to Child Anxiety ……………............................................... 2

The Mechanistic Role of Parent Emotion Socialization ............................................................... 4

The Mechanistic Role of Child Emotion Regulation …………............................................... 7

Parent Emotion Socialization and Child Emotion Regulation as Intermediary Variables ..... 10

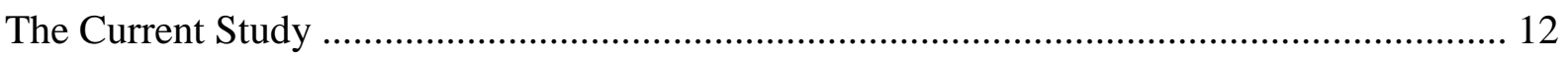

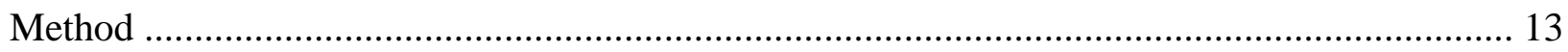

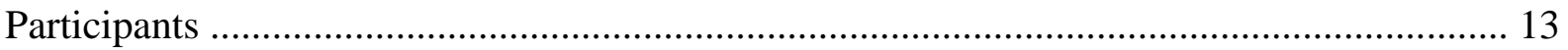

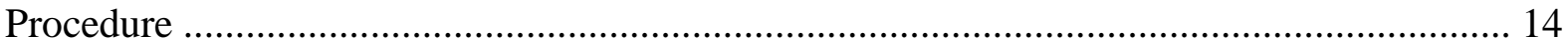

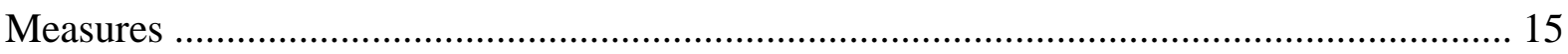

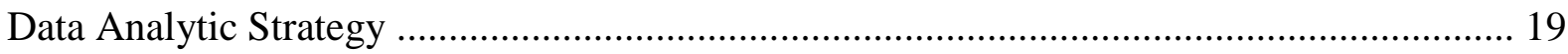

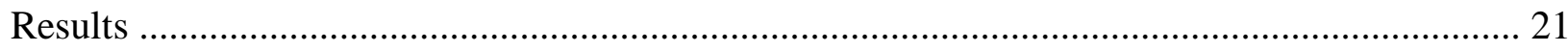

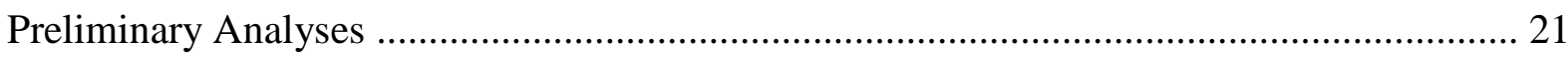

Measurement Model of Child Anxiety ........................................................................... 23

Primary Structural Equation Models ……………………............................................... 24

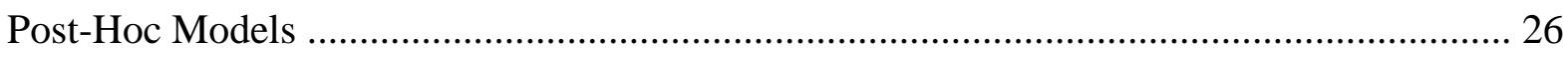

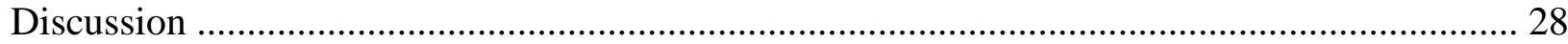

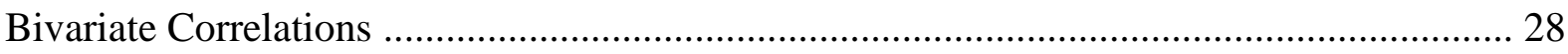

Main and Post-Hoc Structural Equation Models ………….............................................. 29

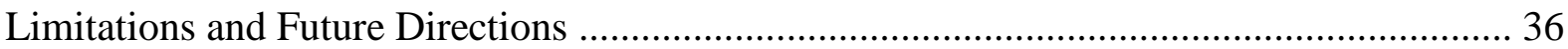

Conclusions and Implications for Research and Clinical Practice ......................................... 38

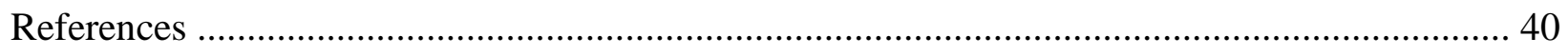

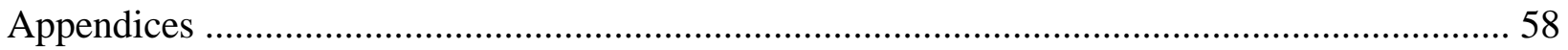




\section{List of Tables}

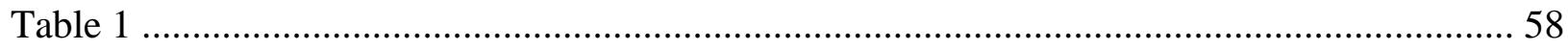

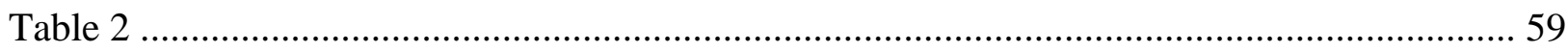




\section{List of Figures}

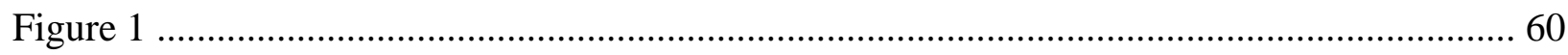

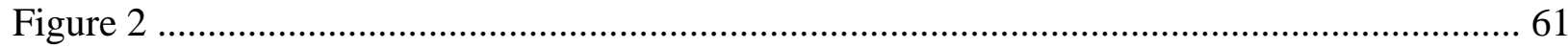

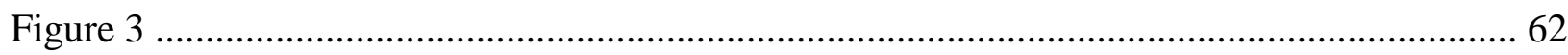

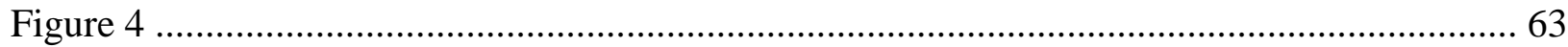

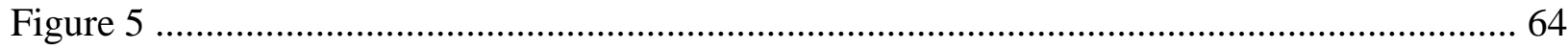

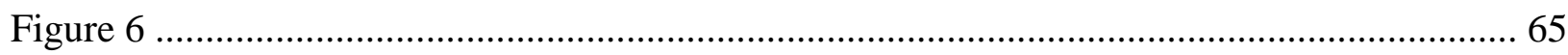

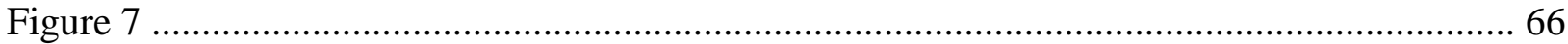

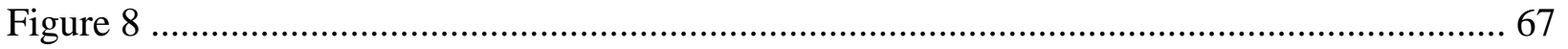




\section{Introduction}

Childhood anxiety has been conceptualized as encompassing children's physiological arousal, threat-focused cognitions, and avoidance-oriented behaviors associated with their “diffuse, objectless apprehension” (Barlow, 2004, p. 7; Ollendick, Grills, \& Alexander, 2001). Between $2.4 \%$ and $22 \%$ of children have clinical levels of anxiety, with rates depending on definitions of functional impairment (Chavira, Stein, Bailey, \& Stein, 2004a; Costello, Mustillo, Erkanli, Keeler, \& Angold, 2003; Franz et al., 2013). Looking beyond clinically-anxious children, many typically-developing children do worry every now and then (e.g., about academic or social troubles; Muris et al., 1998), with up to $30 \%$ of these children still showing patterns of excessive worry despite falling below the threshold for a clinical diagnosis of anxiety (BellDolan, Last, \& Strauss, 1990). As such, it is likely that children experiencing heightened levels of subclinical anxiety may still exhibit some degree of impairment in their daily functioning and may even be at risk for the development of later anxiety disorders.

Child anxiety also remains a critical area of research because of its comorbidity with other mental disorders. Estimates of the number of anxious children with a secondary anxiety disorder diagnosis range from 39-55\% (Angold, Costello, \& Erkanli, 1999; Ollendick et al., 2001; Seligman \& Ollendick, 1998; Tandon, Cardeli, \& Luby, 2009), and many children with anxiety also have heightened depressive symptomatology (Costello et al., 2003; Franz et al., 2013; Seligman \& Ollendick, 1998; Zahn-Waxler, Klimes-Dougan, \& Slattery, 2000) or externalizing disorders (Ollendick et al., 2001). Thus, studies examining the development of child anxiety may have transdiagnostic implications for the origins and maintenance of other disorders.

Despite its prevalence, relevance to community samples, and comorbidity with other disorders, child anxiety remains a disorder whose precedents and mechanistic underpinnings are not entirely understood (Chavira et al., 2004a; Zahn-Waxler et al., 2000). Much recent research utilizes a developmental psychopathology approach for studying child anxiety, which allows for greater examination of the ways in which normative family- and child-level processes may go awry and contribute to the onset of anxiety (Franklin, Jamieson, Glenn, \& Nock, 2015; Sroufe, 2009; Sroufe \& Rutter, 1984; Thompson, 2001). This perspective emphasizes the trajectory and development of psychopathology over clinical symptom manifestation and diagnosis, and it offers insight into resiliency processes that may buffer children against developing anxiety 
(Sroufe \& Rutter, 1984). The current study employs the developmental psychopathology approach to study the etiological underpinnings of child anxiety symptomatology in young children (ages 2-4 years old), in hopes that findings may (a) answer questions regarding how anxiety may emerge over the first few years of life and (b) inform preventative efforts. The focus on early childhood is critical, given that child anxiety symptoms have been shown to emerge early in development and predict children's later anxiety outcomes (Briggs-Gowan, Carter, Bosson-Heenan, Guyer, \& Horwitz, 2006; Mian, Wainwright, Briggs-Gowan, \& Carter, 2011; Tandon et al., 2009; Warren, Umylny, Aron, \& Simmens, 2006).

Recent models of processes precipitating child psychopathology have also focused on elucidating distal transdiagnostic factors that may operate through more proximal mechanisms (Nolen-Hoeksema \& Watkins, 2011). By way of example and as pertinent to the current study, mothers' emotion-related characteristics (e.g., their emotion dysregulation) may distally foster child anxiety development through more proximal emotion-related maternal behaviors and child characteristics. Specifically, both maternal socialization of child emotions and children's own emotion regulation abilities have each been linked to mother emotion dysregulation and child anxiety (e.g., Bariola, Hughes, \& Gullone, 2012; Buckholdt, Parra, \& Jobe-Shields, 2014; Suveg, Zeman, Flannery-Schroeder, \& Cassano, 2005; Thompson, 2001), but no study to date has holistically and explicitly tested these processes as mediators of the predictive relation between mother emotion dysregulation and child anxiety. Thus, maternal emotion dysregulation may be a salient factor contributing to child anxiety and that maternal emotion socialization and child emotion regulation may be mechanisms underpinning this association.

\section{Parent Characteristics Salient to Child Anxiety}

Parents have long since been implicated in the development and maintenance of their children's anxiety (Bögels \& Phares, 2008; Fendrich, Warner, \& Weissman, 1990; Murray, Creswell, \& Cooper, 2009). Nonetheless, little research has explicitly examined the association between maternal emotion dysregulation and child anxiety. Indirect evidence for this prospective linkage may be found in the literature on the role of parent psychopathology (especially parent anxiety) in child anxiety development. Parents' anxiety disorders, anxious attitudes, and anxious behaviors put children at risk for maladaptive outcomes, including anxiety (Beidel \& Turner, 1997; Bögels \& Phares, 2008; Cooper, Fearn, Willetts, Seabrook, \& Parkinson, 2006; Grüner, Muris, \& Merckelbach, 1999; Lieb et al., 2000; Merikangas, Dierker, \& Szatmari, 1998; Muris 
\& Merckelbach, 1998; Murray et al., 2009). Many of these studies have focused on and demonstrated the salience of maternal anxiety to children's anxiety disorders (Cooper et al., 2006; Martini, Knappe, Beesdo-Baum, Lieb, \& Wittchen, 2010; McClure, Brennan, Hammen, \& Le Brocque, 2001). There is a related body of research showing that parents who are depressed or have depression and anxiety may also have children with greater anxiety (Barker, Jaffee, Uher, \& Maughan, 2011; Beidel \& Turner, 1997; Fendrich et al., 1990; Goodman et al., 2011; Hughes \& Gullone, 2010b; Lieb et al., 2000). Researchers have postulated that parental characteristics and/or behaviors that transcend diagnoses may ultimately give rise to child anxiety and be most salient to intervention efforts (Berg-Nielsen, Vikan, \& Dahl, 2002; Maliken \& Katz, 2013). Given its role in both adult anxiety and depression (Aldao, Nolen-Hoeksema, \& Schweizer, 2010; Hofmann, Sawyer, Fang, \& Asnaani, 2012; Maliken \& Katz, 2013; Mennin, Heimberg, Turk, \& Fresco, 2005; Suveg, Morelen, Brewer, \& Thomassin, 2010), parent emotion regulation may be one such transdiagnostic factor.

In this context, emotion regulation refers to the ways in which individuals (e.g., parents) tend to monitor, evaluate, and modify their emotional experiences and expressions (Thompson, 1994, 2001). Extending beyond mere deficits in emotion regulation, the concept of emotion dysregulation provides a pertinent measure of dysfunctional characteristics and behaviors pertinent to psychopathology development, capturing the extent to which individuals engage in more maladaptive and fewer adaptive ways of managing their emotions (Gratz \& Roemer, 2004; Thompson, 2019). Both Eisenberg et al. (1998) and Morris et al. (2007) posit that parents' emotion-related characteristics (e.g., how they regulate emotions in maladaptive ways) may both directly and indirectly impact their children's psychological adjustment. Directly, recent research suggests that mothers' emotion dysregulation when pregnant relates to their newborns' excitability, irritability, and agitation (Ostlund et al., 2019). Moreover, parental emotion dysregulation may operate to influence child outcomes through parent emotion socialization practices and child emotion regulation. In terms of relating parent emotion dysregulation specifically to child internalizing disorders, Yap and colleagues' (2007) integrative model of family emotion processes proposes that parent emotion dysregulation may play a role in adolescent internalizing symptomatology. Furthermore, another study's model of emotion processes predicting adolescent internalizing and externalizing symptoms incorporated parent emotion dysregulation as a distal factor but did not (a) assess the direct association between 
parent emotion dysregulation and child internalizing symptomatology or (b) examine the linkages over time (Buckholdt et al., 2014). However, as one of the only studies to directly assess this relation, Han and Shaffer (2013) found that parent emotion dysregulation predicted greater internalizing symptomatology in children ages 8-11 years old, but only for children who were highly prone to maladaptively internalizing their negative emotions. In summary, there is much evidence for these prospective relations via the robust parent psychopathology literature and only very limited direct preliminary evidence. Moreover, there is a need for examination of potential mediators of this association, and as such, the current study proposes maternal emotion socialization and child emotion regulation as two such mechanisms underlying these linkages.

\section{The Mechanistic Role of Parent Emotion Socialization}

Researchers have conceptualized parents as emotional role models for their youth, providing the foundation for their children's emotional development (Zeman, Cassano, \& Adrian, 2013). As primary figures of support, parents aid the development and honing of their children's skills to display, understand, and regulate their emotions, starting when their children are in infancy and continuing throughout their childhood (Denham, Bassett, \& Wyatt, 2007; Malatesta \& Haviland, 1982; Morris, Houltberg, Criss, \& Bosler, 2017; Morris et al., 2007). Emotion socialization provides one venue through which parents may do so, encompassing the process by which socialization agents (e.g., parents) impart their values, beliefs, and practices regarding the acceptability of emotional expressivity to their children (Eisenberg et al., 1998; Zeman et al., 2013). In the past few decades, researchers have identified several indirect and direct modes by which parents socialize their children's emotions. The current study focuses on how parents (mothers, specifically) directly socialize their children's emotions via responding to their children's emotional displays in supportive or unsupportive ways.

There exists a broad range of verbal and nonverbal responses that parents may directly provide to their children's emotional displays (Eisenberg et al., 1998). These responses may be supportive or unsupportive in nature, and parents may respond in both ways to their child, even within the same setting and discussion (Klimes-Dougan et al., 2007; Lunkenheimer, Shields, \& Cortina, 2007; Miller-Slough \& Dunsmore, 2016; Sanders, Zeman, Poon, \& Miller, 2015). Specifically, supportive responses may include parents encouraging and validating their children's emotional expressions (e.g., by assuring them that it is okay to feel sad sometimes), providing their children with emotional comfort to alleviate distress (e.g., by soothing them), 
and/or helping their children solve their emotional problem (Fabes, Poulin, Eisenberg, \& Madden-Derdich, 2002; Klimes-Dougan et al., 2007). In contrast, parents may unsupportively ignore, punish (e.g., by scolding them or threatening removal of a privilege), or minimize (e.g., by saying they are overreacting and should "get over it") their children's emotional displays, or even become highly distressed themselves (Fabes et al., 2002; O’Neal \& Magai, 2005). Importantly, supportive and unsupportive emotion responses appear to be conceptually distinct, with parents engaging in varying amounts of both (Fabes, Eisenberg, \& Bernzweig, 1990).

Parent emotion regulation and dysregulation predict parent emotion socialization.

Holistic models of family emotion processes provide a theoretical foundation for the existence of these linkages. Aforementioned seminal models of antecedents and consequences of emotion socialization practices by Eisenberg et al. (1998) and Morris et al. (2007) both propose that parents' characteristics (e.g., their emotion regulation and dysregulation) may impact how they socialize their children's emotions. Indeed, several studies are beginning to examine the impact of parents' emotion regulation on their emotion socialization patterns. Hughes and Gullone (2010a) found that although parents' use of emotion regulation strategy use (i.e., suppression, reappraisal) did predict their socialization responses, parents' personality traits (e.g., agreeableness) accounted for a larger portion of the variance in socialization responses. Still, their findings do offer preliminary evidence that parents who utilize suppression to manage their negative emotions may be more likely to punish or minimize their children's expressions of negative emotions (Hughes \& Gullone, 2010a). In another study, Buckholdt et al. (2014) found that parents with greater emotion dysregulation were more likely to invalidate their youths' emotional expressions. Similar results have been found in other samples, with greater observed or reported parent emotion dysregulation predicting parents' more unsupportive emotion socialization practices towards their youth (Morelen, Shaffer, \& Suveg, 2016; Yan, Han, \& Li, 2016). There is also some evidence (at least in Indian American samples) that mothers with less emotion dysregulation may engage in more supportive responses towards their children's emotion displays (Raval, Walker, \& Daga, 2018). However, more research is needed to corroborate these initial trends and to understand them in younger samples and across time.

Parent emotion socialization predicts child anxiety. In general, parents' behaviors (e.g., controlling, overprotective, emotionally negative behaviors) towards their children do appear to contribute to their children's greater anxiety symptoms (Bögels \& Phares, 2008; 
Edwards, Rapee, \& Kennedy, 2010; Lieb et al., 2000; Mcleod, Wood, \& Weisz, 2007; Murray et al., 2009; van der Bruggen, Stams, \& Bögels, 2008). However, general indices of parenting may not be the most effective targets for understanding child anxiety. A meta-analysis by McLeod and colleagues (2007) found that parenting variables only accounted for $4 \%$ of the variance in child anxiety outcomes. Other researchers have lent further support to these results, finding main effects for the transmission of maternal anxiety to child anxiety but a lack of indirect effects through parenting behaviors (McClure et al., 2001).

Parental emotion socialization, however, seems to be more robustly related to child anxiety outcomes. Parents' supportive and unsupportive emotion socialization responses are generally associated with their children's adaptive and maladaptive outcomes, respectively (for reviews, see Eisenberg et al., 1998; Miller-Slough \& Dunsmore, 2016). Along these lines, supportive emotion socialization practices have been linked to youths' lower rates of anxiety and broader indices of internalizing symptomatology (Buckholdt et al., 2014; Hooper, $\mathrm{Wu}, \mathrm{Ku}$, Gerhardt, \& Feng, 2018; Hurrell, Hudson, \& Schniering, 2015; Mirabile, Oertwig, \& Halberstadt, 2016; Thompson \& Meyer, 2007). In contrast, parental engagement in unsupportive emotion socialization practices, particularly that which involves neglecting and punishing responses towards their children's negative emotions, appears to contribute to children's greater internalizing symptoms (O’Neal \& Magai, 2005; Sanders et al., 2015; Schwartz, Sheeber, Dudgeon, \& Allen, 2012; Williams \& Woodruff-Borden, 2015). In fact, Suveg and colleagues (2005) illustrated that mothers of clinically-anxious children tend to show more discouragement of their children's emotional expressions and less emotional expressivity in the family context. All the same, it is important to concede that parents' unsupportive emotion socialization strategies may not always necessarily be associated with their children's worse anxiety outcomes. For instance, some research (including that in non-white samples) has failed to find links between parents' emotion socialization responses to their children's emotions and children's internalizing symptoms (Suveg, Shaffer, Morelen, \& Thomassin, 2011; Tao, Zhou, \& Wang, 2010). Further, results from one study suggest that mothers' minimizing responses to emotion displays may serve to actually help anxious children interpret ambiguous situations in more appropriate ways (Viana, Dixon, Stevens, \& Ebesutani, 2016). Thus, it is possible that certain emotion responses may function as supportive or unsupportive, depending on cultural context. Still, the overwhelming state of the literature suggests that parents' supportive and 
unsupportive reactions to their children's emotions are respectively adaptive and maladaptive for child anxiety development.

Given (a) associations between parents' emotion regulation/dysregulation and emotion socialization practices and (b) established links between parent emotion socialization and child anxiety, I anticipate that parent emotion socialization may serve as an intermediary mechanism between parents' emotion dysregulation and their children's anxiety symptomatology. That is, the ways that parents regulate their emotions in maladaptive ways may contribute to their children's anxiety through parental socialization of children's emotions. However, parent emotion socialization may not be the only mediator in this relation and may itself be mediated as part of a serial transmission process.

\section{The Mechanistic Role of Child Emotion Regulation}

Beginning in infancy and toddlerhood, children begin developing adaptive and effective (or maladaptive and inappropriate) skills to regulate their emotions (Cole, Dennis, Smith-Simon, \& Cohen, 2009; Zahn-Waxler et al., 2000), thereby showing early individual differences in their regulatory abilities (Bridges \& Grolnick, 1995; Grolnick, Bridges, \& Connell, 1996). Over time, these basic regulatory strategies tend to become more sophisticated, flexible, and self-initiated (Calkins, 1994; Calkins \& Hill, 2007; Thompson \& Calkins, 1996). By early toddlerhood, most children have made substantial gains in their emotion-related capabilities and have transitioned from near-exclusive dependence on caregivers for emotion management to voluntary, purposeful engagement in their own emotion regulation strategy use (Bridges \& Grolnick, 1995; Calkins, 2007; Calkins \& Hill, 2007; Kopp, 1989; Thompson \& Goodvin, 2007). Young children engage in a variety of adaptive emotion regulation behaviors (Calkins \& Hill, 2007; Cole, Martin, \& Dennis, 2004; Grolnick et al., 1996), including caregiver-seeking and attention-shifting behaviors which are among some of the most well-studied regulatory strategies.

Toddlers employ caregiver-focused behaviors when they look towards their caregiver for reassurance or seek out closer contact with them during distressing situations (Buss, Brooker, \& Leuty, 2008; see also Kopp, 1989). That is, a child may look back towards his mother for a "check-in" that he is safe and perhaps even run towards her if he is frightened by a novel, remote-controlled robot. Caregiver-focused emotion regulation behaviors occur contingently with decreases in child distress (Buss \& Goldsmith, 1998; Calkins, Gill, Johnson, \& Smith, 1999; Diener \& Mangelsdorf, 1999). Toddlers may also regulate their distress by altering their 
visual attention via either briefly averting their gaze from a distressing stimulus or by visually focusing on a source of distraction for longer periods of time (Bridges \& Grolnick, 1995; Calkins, 2007; Mangelsdorf, Shapiro, \& Marzolf, 1995). By way of example, a child may engage in brief looks away from an unfamiliar adult or visually concentrate on his toy as a means of regulating his distress. Similar to caregiver-focused behaviors, this attention-focused regulatory strategy does appear to be effective in alleviating children's distress (Buss \& Goldsmith, 1998;

Crockenberg \& Leerkes, 2004; Stifter \& Braungart, 1995), whereas deficits in these abilities tend to be associated with children's greater negative arousal (Calkins, 2007).

\section{Parent emotion regulation and dysregulation predict child emotion regulation.}

Theory and recent evidence suggests a link between parent emotion regulation/dysregulation and child emotion regulation (Bariola, Gullone, \& Hughes, 2011; Ostlund et al., 2019; Yap, Allen, \& Sheeber, 2007). Indeed, there is likely a genetic component to the intergenerational transmission of emotion regulation/dysregulation from parent (e.g., mother) to child that is important to acknowledge (Goldsmith, Pollak, \& Davidson, 2008; Ostlund et al., 2019), although little research has focused on these relations at a neurobiological level. Considering relations as they may exist at an environmental level, mothers' emotion regulation strategy use does appear to contribute to their children's utilization of similar strategies (e.g., emotion suppression; Bariola et al., 2012; Silva, Freire, \& Faria, 2018). Moreover, one recent study found that mothers who engaged in fewer emotion suppression strategies had children with better emotion regulation abilities, over and above the effects of mothers' supportive emotion socialization responses and children's emotionality (Rogers, Halberstadt, Castro, Maccormack, \& Garrett-Peters, 2016). Other findings have similarly illustrated that this intergenerational transmission of emotion dysregulation may hold for mothers and their children concurrently (Morelen et al., 2016) and for fathers and their older children (ages 17 to 19 years old) longitudinally (Kim, Pears, Capaldi, \& Owen, 2009). Consistent trends were observed in Buckholdt et al. (2014), with more emotionally dysregulated parents having children with greater difficulties regulating emotions. Thus, it appears that there may be an association - both genetically and environmentallybetween parents' and children's emotion regulation abilities.

Child emotion regulation predicts child anxiety. A separate burgeoning area of research has revealed that young children's temperamental characteristics, particularly their emotion-oriented traits (e.g., children's emotion regulation), may predispose them to anxiety risk 
(Carthy, Horesh, Apter, \& Gross, 2010; Cisler, Olatunji, Feldner, \& Forsyth, 2010). Along these lines, a variety of studies and theoretical papers have proposed and examined the role of emotion regulation deficits or maladaptive strategies in the development and maintenance of anxiety (Carthy et al., 2010; Folk, Zeman, Poon, \& Dallaire, 2014; Suveg \& Zeman, 2004). Dysregulated emotions may be inherent to anxiety development (Hurrell et al., 2015; Thompson, 2001), with many internalizing disorders seen as "core disturbances in intropunitive emotions and moods" (Zahn-Waxler et al., 2000, p. 2-3). Researchers postulate that internalizing symptomatology may involve intensified or a greater sensitivity to negative emotions, as well as heightened efforts to suppress such emotional expressions, which may be most detrimental in the absence of parental emotional support (Han \& Shaffer, 2013; Thompson, 2001). Along these lines, dysregulated affect, the inability to identify emotional states, and less constructive coping all predict internalizing symptomatology, above and beyond baseline internalizing symptoms (McLaughlin, Hatzenbuehler, Mennin, \& Nolen-Hoeksema, 2011; Zeman, Shipman, \& Suveg, 2002). Regarding anxiety specifically, a lack of emotional understanding and acceptance of negative emotions, as well as limited overall access to a repertoire of emotion regulation strategies, has also been found to relate to child anxiety (Lougheed \& Hollenstein, 2012; Neumann, van Lier, Gratz, \& Koot, 2010). In a related line of research, researchers have demonstrated that toddlers' engagement in emotion regulation strategies may be indicative of and even prospectively related to their better self-regulatory abilities (e.g., attentional control, effortful control; Bridges \& Grolnick, 1995; Calkins, 2007; Calkins \& Hill, 2007; Graziano, Calkins, \& Keane, 2011; Kopp, 1989), deficiencies of which are implicated in child anxiety (Eisenberg et al., 2009; Muris, van der Pennen, Sigmond, \& Mayer, 2008). Thus, although fewer studies to date have assessed the role of toddlers' specific emotion regulation strategies in anxiety development, the robust link between various indices of child emotion regulation and child anxiety supports my conceptualization of attention- and caregiver-focused emotion regulation behaviors as being associated with later anxiety symptomatology.

Nevertheless, it is important to note that there exist a few studies suggesting that such emotion regulation strategies may not always be especially helpful for children (e.g., Buss \& Goldsmith, 1998; Diener \& Mangelsdorf, 1999). For example, young children who over-rely on proximity to and reassurances from parents may be at risk for the development of maladaptive family behavioral cycles often implicated in child anxiety. That is, these child behaviors, in 
excess, may reinforce children's dependency on their parents during novel or fearful contexts, which may then undermine the growth of their abilities to regulate their emotions on their own (Bögels \& Brechman-Toussaint, 2006; Dadds \& Roth, 2001; Thompson \& Calkins, 1996). In a similar way, children's exclusive reliance on shifting visual attention from distressing stimuli could potentially foster maladaptive cycles of avoidance, given that visual vigilance-avoidance patterns have been observed in children with anxiety disorders (In-Albon, Kossowsky, \& Schneider, 2010). However, the larger corpus of research on the association between child emotion regulation and anxiety lends itself to expectations that children's fewer emotion regulation behaviors would be related to their greater anxiety symptomatology.

\section{Parent Emotion Socialization and Child Emotion Regulation as Intermediary Variables}

Beyond parent emotion socialization and child emotion regulation individually functioning as mechanisms in the association between parent emotion dysregulation and child anxiety, these mediators may also operate serially. That is, parents' emotion regulation abilities may engender their subsequent emotion socialization practices, which may then contribute to how their children regulate emotions. In turn, the ways that children regulate emotions may contribute to their anxiety over time.

There is some precedence for these linkages. For one, parent emotion socialization and child emotion regulation are empirically linked. Specifically, through parents' supportive responses to their emotions, youth may learn positive ways to understand, regulate, and cope with emotions (Eisenberg et al., 1998; Hurrell et al., 2015; Shipman et al., 2007; Thompson \& Meyer, 2007). Mothers who facilitate their children's engagement in regulating behaviors have children who verbalize and exhibit more effective emotion regulation strategies (Cole et al., 2009) and are better able to identify emotional states (Fabes et al., 2002). Moreover, particularly in younger children, greater supportive parental responses relate to children's more adaptive emotion regulation skills (e.g., more caregiver- and attention-focused regulatory behaviors) and characteristics (Calkins \& Johnson, 1998; Mirabile et al., 2016).

On the other hand, unsupportive parental responses (e.g., neglecting, punishing) contribute to children's greater emotion dysregulation (Buckholdt et al., 2014; Shipman et al., 2007; Williams \& Woodruff-Borden, 2015). These unsupportive responses have been implicated in prolonging and intensifying youths' emotional states (Fabes, Leonard, Kupanoff, \& Martin, 2001), hindering their emotion-related coping strategies (Sanders et al., 2015; Thompson \& 
Meyer, 2007), and contributing to their dysregulated affect and deficits in abilities to recognize emotions (Brand \& Klimes-Dougan, 2010; Buckholdt et al., 2014; Fabes et al., 2002). More generally, too, mothers' greater negative, controlling parenting behaviors are associated with children's lower utilization of attention-oriented emotion regulation behaviors (Calkins, Smith, Gill, \& Johnson, 1998). In this way, parents' discouraging and minimizing responses may function to (a) teach children to suppress their emotions and associated physiological arousal and (b) hinder children's development of emotion regulation skills (Fabes et al., 2001).

Importantly, too, several researchers have conceptualized parent emotion socialization as a mechanism of the relation between parent emotion dysregulation and child emotion regulation. For instance, work by Shaffer and colleagues has begun to address this possibility. Morelen et al. (2016) assessed these relations and did not find a statistically significant indirect effect.

However, greater mother emotion dysregulation did relate to constructs similar to child emotion regulation - greater child negativity and emotionality — through mothers' unsupportive emotion socialization behaviors. In another study, Are and Shaffer (2016) examined a sample of mothers and their preschool children, finding an indirect effect between greater mother emotion dysregulation and worse child emotion regulation through less positive family expressiveness. Indeed, other researchers have suggested that parents' dysregulated ways of managing emotions may engender their inappropriate and unsupportive responses to their children's emotions, which may in turn contribute to their children's worse emotion regulation (Bariola et al., 2011).

Given the strong relations between parent emotion socialization practices and children's emotion regulation, as well as the demonstrated role of emotion regulation deficits in child anxiety, it follows that child emotion regulation may be a mechanism through which parent emotion socialization practices predict child anxiety. Specifically, children who expect fewer supportive and more unsupportive responses from their mothers may learn to regulate their emotional expressivity in deleterious ways (e.g., suppression) that promote anxiety risk (Suveg et al., 2005). Along these lines, Han and Shaffer (2013) found that parent emotion dysregulation contributed to children's greater internalizing symptomatology, particularly for children who tended to suppress their negative emotions. Additionally, the link between child emotion dysregulation and depressive symptoms (which tend to carry diagnostic overlap with anxiety symptoms; Chavira, Stein, Bailey, \& Stein, 2004b; Franz et al., 2013) may be most strong for children whose parents engage in highly unsupportive emotion socialization practices (Sanders et 
al., 2015). Perhaps of most direct relevance, Buckholdt and colleagues (2014) recruited an adolescent-parent dyad sample and found that parental invalidation predicted adolescents' internalizing behaviors through adolescents' emotion dysregulation. These findings are promising and further demonstrate the need for more research into this potential mechanistic relation in a younger sample and across time.

\section{The Current Study}

Given this background and the continued prevalence of child anxiety (Chavira et al., 2004a; Franz et al., 2013; Ollendick et al., 2001), there still exists a great need for research addressing the etiological underpinnings of elevated anxiety among young children. Transdiagnostic parent characteristics (i.e., maternal emotion dysregulation) and behaviors (i.e., maternal emotion socialization), as well as children's early-emerging emotion regulation attempts, may collectively be relevant to anxiety risk in early childhood. As such, the current study examined how maternal emotion dysregulation may influence mothers' emotion socialization (either supportive or unsupportive) and children's emotion regulation (either attention- or caregiver-focused) over time, with a primary emphasis of how these emotion processes may contribute to later child anxiety. While this research was driven by preliminary evidence of linkages between study variables, there remained a demonstrated need for an integrated model of these processes over time. Three time-points were utilized-namely, when children were ages 2, 3, and 4 years old (Time 1, Time 2, and Time 3 respectively). Using a longitudinal, multi-method approach, the present study addressed critical gaps in the extant literature by linking emotion processes pertinent to the etiology of child anxiety. Thus, the following hypotheses were evaluated:

1. Greater maternal emotion dysregulation at Time 1 (T1) will relate to more negative maternal emotion socialization (i.e., less supportive, more unsupportive) and fewer child caregiver- and attention-focused emotion regulation attempts at Time 2 (T2), as well as greater child anxiety at Time $3(\mathrm{~T} 3 ;$ Aim 1).

2. For Aim 2, there will be five indirect effects present in each of the four models of these processes that involve associations in the same directions specified in Aim 1. Specific indirect effects to be assessed include: (1) mother emotion dysregulation to child emotion regulation through maternal emotion socialization, (2) maternal emotion dysregulation to child anxiety through child emotion regulation, (3) maternal emotion dysregulation to 
child anxiety through maternal emotion socialization, (4) maternal emotion socialization to child anxiety through child emotion regulation, and (5) maternal emotion dysregulation to child anxiety through maternal emotion socialization and child emotion regulation serially.

\section{Method}

\section{Participants}

Participants were 175 mothers and their toddlers ages $2-4$ (57.1\% boys, $42.9 \%$ girls) who were recruited in the midwestern United States as part of a larger study (Project number: 1R15HD076158-01, PI: E. Kiel). Some participating families from the larger study had multiple children participating. To reduce shared same-family reporter variance and ensure participant independence, only one child was chosen from each family based on their availability of measures at each time point, thereby excluding 20 participants for a final sample of 175 families. In the final sample, $93.1 \%$ of mothers were non-Hispanic, $1.7 \%$ were Hispanic, and $5.1 \%$ declined to answer, while $90.9 \%$ of toddlers were non-Hispanic, $3.4 \%$ were Hispanic, and $5.7 \%$ declined to answer. Regarding race, mothers were $89.7 \%$ European American, $2.9 \%$ Asian or Pacific Islander, 0.6\% African American, 0.6\% Latinx, 0.6\% Native American, and 0.6\% identifying with multiple races. Nine mothers declined to provide their race. Most toddlers (81.1\%) were European American, although African Americans (1.7\%), Asian or Pacific Islanders $(1.1 \%)$, Latinx $(1.1 \%)$, and individuals identifying with multiple races $(9.1 \%)$ were also represented, with an additional $5.7 \%$ of the sample not providing information about their race. Families were mostly lower- to upper-middle class, with annual family incomes ranging from less than $\$ 15,000$ to over $\$ 100,000$ and averaging between $\$ 51,000-60,000$ per year. Participating mothers averaged 15.47 years of formal education, ranging from a $11^{\text {th }}$ grade to a doctoral degree.

Mothers were recruited through the mail from locally published birth announcements and from local community programs and offices (e.g., the Women, Infants, and Children program, farmer's markets, child-care centers, pediatricians' offices). Mothers had to be at least 18 years old and able to read and write in English to be eligible. Families enrolled in the study at any of the three data-wave time-points (Time 1, 2, or 3). Families came in for T1 when children were between 24-30 months old (T1 $M_{\text {age }}=26.77$ months), T2 when children were between 36-42 months of age (T2 $M_{\text {age }}=39.10$ months), and T3 when children were between $48-54$ months old 
(T3 $M_{\text {age }}=51.84$ months). Most families (145) enrolled at T1, with 21 enrolling at T2, and 9 enrolling at T3. Data-wise, $82.8 \%$ of families had data for T1, 73.1\% of families had data for T2, and $53.7 \%$ had data for T3. Further, $38.3 \%$ of families had data for three time-points, $32.6 \%$ had two time-points, and $29.1 \%$ had one time-point.

\section{Procedure}

Researchers obtained university institutional research board approval for the larger study. Mothers provided written informed consent at Times 1, 2, and 3. Mothers showed their interest in participating via signing up in-person at community programs or by replying to a mailed, emailed, or phoned-in participation invitation. Graduate research assistants called or emailed mothers who expressed interest to coordinate a laboratory visit and mailed them each a packet of questionnaires. Mothers then returned their packets when they came into the laboratory and received an explanation of the activities. The family visits lasted between 1.5-3 hours, depending on the time point. At each time point, mothers were debriefed verbally and in writing. Mothers were compensated $\$ 50$ and children received a small gift (worth $<\$ 5$ ) for their participation at each time-point.

Time 1 visit. Once mothers indicated their willingness to participate in the larger study, they received and returned a consent form, basic demographic information ${ }^{1}$, and the questionnaire assessing maternal emotion dysregulation. They were then scheduled for and participated in a lab visit that involved a variety of tasks, but only questionnaire data at Time 1 is being used for the present study.

Time 2 visit. Approximately one year later, mothers were sent (and then returned) questionnaires assessing their emotion socialization responses. Mothers then came into the laboratory with their children to participate in several activities based on the Laboratory Temperament Assessment Battery episodes for toddlers (Lab-TAB; Buss \& Goldsmith, 2000; Goldsmith, Reilly, Lemery, Longley, \& Prescott, 2001) and previous studies in the literature (Buss, 2011; Nachmias, Gunnar, Mangelsdorf, Parritz, \& Buss, 1996). Activities pertinent to the current study involved (a) a research assistant dressed up as a clown and (b) a remote-controlled spider.

\footnotetext{
${ }^{1}$ Mothers who did not participate at T1 but began participating at T2 or T3 answered the basic demographic questions during their first visit to the lab.
} 
With respect to the 5-minute "clown" episode, children and their mothers were shown into an empty room and instructed to wait for the game to start. Several seconds later, a research assistant dressed like a clown (i.e., clown costume, wig, red nose) opened the door and entered the room. She introduced herself as "Floppy" the clown in a friendly tone of voice and invited the child to play with the toys in her bag. Specifically, she took out and proceeded to play three games (blowing bubbles, catching beach balls, shaking musical instruments) with the child, each of which lasted approximately 1 minute in length. She also removed her wig and red nose at the start of the third game. At the conclusion of the games, the research assistant asked the child to help clean up before saying goodbye to the family and leaving the room.

Regarding the 1-minute "spider" episode, children and their mothers were again shown into an empty room and were instructed to begin seated in a chair with the toddler on their mother's lap. A remote-controlled spider (controlled by a research assistant) approached halfway to the mother's chair, paused for 10 seconds, and backed up to its original starting place. After waiting another 10 seconds, the spider then approached close to the mother's chair. The spider again paused for 10 seconds and then retreated to its original starting place. A research assistant then entered the room and prompted the child three times to come touch the spider. Whether the child chose to touch the spider or not, they were then debriefed that the spider was just a toy (and the experimenter touched it). Both the clown and spider episodes were video- and audio-recorded for later behavioral coding.

Time 3 visit. Approximately one year later, mothers again received and sent questionnaires that provided age-appropriate assessments of their child's anxiety symptomatology. They then similarly participated in a lab visit not pertinent to the current study.

\section{Measures}

Mother emotion dysregulation (Time 1). Mothers completed the 36-item Difficulties in Emotion Regulation Scale (DERS; Gratz \& Roemer, 2004) that assessed their emotion dysregulation along six dimensions: nonacceptance of emotional responses, difficulties engaging in goal directed behavior, impulse control difficulties, limited access to emotion regulation strategies, lack of emotional awareness, and lack of emotional clarity (e.g., 'When I'm upset, I feel guilty for feeling that way,' 'When I'm upset, I lose control over my behaviors'). Mothers responded to items on a 5-point scale $(1=$ Almost never $[0-10 \%$ of the time $]$ to $5=$ Almost always [91-100\% of the time]), with respect to how often the items applied to themselves. A 
mean composite emotion dysregulation score was computed by averaging all items $(\alpha=.94)$. In past studies, the DERS scale has demonstrated acceptable to high test-retest and internal reliability, as well as construct validity (e.g., with respect to other measures of emotion regulation, emotional expressivity, experiential avoidance) and predictive validity (e.g., in terms of clinically-relevant behavioral outcomes; Gratz \& Roemer, 2004). It has been used with parents in past studies (e.g., Buckholdt et al., 2014; Morelen et al., 2016).

Mother emotion socialization (Time 2). Mothers reported on how they respond to their toddlers' negative emotions via the 82-item Coping with Toddlers' Negative Emotions Scale (CTNES; Fabes, Eisenberg, \& Bernzweig, 1990; Spinrad, Eisenberg, Kupfer, Gaertner, \& Michalik, 2004). The CTNES presented 12 hypothetical scenarios to mothers in which their child is experiencing a negative emotion. It was adapted from the Coping with Children's Negative Emotions Scale to be more situationally-relevant for toddlers', rather than children's, negative emotion displays (Fabes et al., 1990, 2002). For each scenario, mothers used a 7-point scale $(1=$ Very Unlikely to $7=$ Very Likely) to identify the likelihood that they would engage in particular responses to their child (e.g., 'If my child loses some prized possession and reacts with tears, I would...'). Mothers indicated their likelihood of engaging in seven different emotion socialization responses for each hypothetical vignette. Both supportive and an unsupportive emotion socialization response composites were created, as has been done in past studies (e.g., Eisenberg et al., 2010; Jacquelyn Gross, 2015; Gudmundson \& Leerkes, 2012; Spinrad et al., 2007). The 36-item supportive emotion socialization responses composite ( $\alpha=.94$; betweensubscale $r \mathrm{~s}=.55-.74, \mathrm{ps} \leq .001)$ was derived from the averages of the Expressive Encouragement (e.g., the extent to which mothers encourage and validate their child's negative emotion displays; $\alpha=.93$ ), Emotion-Focused Reactions (e.g., the degree to which mothers respond with strategies to alleviate their child's negative emotions; $\alpha=.83$ ), and ProblemFocused Reactions subscales (e.g., the extent to which mothers respond to their child's negative emotions by helping them solve their problem; $\alpha=.87$ ) subscales. Example items for these three supportive subscales are 'I would tell my child it's okay to cry', 'I would comfort my child and try to make him/her feel better,' and 'I would help my child think of something else to do,' respectively. The 36-item unsupportive emotion socialization responses composite $(\alpha=.90$; between-subscale $r \mathrm{~s}=.27-.60, \mathrm{ps}=.004-.001)$ was derived from the averages of the Distress Reactions (e.g., the degree to which mothers experience distress when their child expresses 
negative emotions; $\alpha=.83$ ), Minimization Reactions (e.g., the extent to which mothers minimize or devalue their child's negative emotions; $\alpha=.86$ ), and Punitive Reactions subscales (e.g., the degree to which mothers punish their child's negative emotion displays; $\alpha=.82$ ). Respective example items for these three unsupportive subscales include 'I would feel upset and uncomfortable because of my child's reactions', 'I would tell my child that he/she is overreacting,' and 'I would tell my child to behave or we'll have to go home right away.' Given its lack of conceptual overlap and exclusion from past composites, the Wish-Granting Reactions subscale (e.g., the degree to which mothers acquiesce to their child's demands to avoid or alter their child's distressing situation) was not used. The CTNES has been utilized in numerous studies (e.g., Eisenberg et al., 2010; Engle \& McElwain, 2011; Gudmundson \& Leerkes, 2012; Leerkes, Parade, \& Gudmundson, 2011; Spinrad et al., 2007) and has demonstrated acceptable to excellent test-retest and internal reliability, in addition to construct validity (e.g., with respect to other parenting indices; Fabes et al., 2002; Spinrad et al., 2004).

Observed child emotion regulation (Time 2). Child emotion regulation was assessed by examining children's behaviors during the clown and spider episodes. Toddler emotion regulation behaviors were coded by research assistants blind to study hypotheses by using the Lab-TAB manual emotion regulation coding definitions (Buss \& Goldsmith, 2000; Goldsmith et al., 2001) and INTERACT version 14 software (Mangold, 2017). Coders rated toddlers' emotion regulation behaviors as either present/absent on second-by-second basis (25 video frames per second), and inter-rater reliability was calculated at this rate as kappa coefficients and ICCs. Coders split the cases to be coded once they reached a minimum inter-reliability standard with the master coder. The master coder coded approximately $25 \%$ of the cases to ensure continued interrater reliability, and coders met on a weekly basis to prevent coder drift. Caregiver-focused regulation behaviors denoted toddlers' looks towards their caregiver or their self-initiated efforts to increase proximity to their mother. Attention-focused regulation behaviors involved instances in which the toddler engaged in gaze aversion (brief looks away from the clown, lacking an apparent focus) or distraction (looks away from the clown and toward a target for 2 or more seconds). For both categories of behaviors, two scores were derived-namely, a frequency score (i.e., summed discrete instances of their behaviors) and a proportion score (i.e., the total duration of time [or percentage of time] in which they engaged in the behaviors, relative to the duration of observable time in the episode). For the caregiver-focused and attention-focused regulation 
behaviors, kappas (calculated within a range of 2 seconds) ranged from .66-.74 $\left(M_{\mathrm{K}}=.69\right)$ and $.52-.60\left(M_{\kappa}=.55\right)$, respectively. Caregiver-focused behavior frequency and duration ICCs ranged from .90-.98 $\left(M_{I C C}=.95\right)$, while attention-focused behavior ICCs ranged from .77-.91 $\left(M_{I C C}=\right.$ .85). To account for the tradeoffs conferred in using either frequency- or proportion-based scores, both factors were incorporated into the final composites. Specifically, for each episode, the frequency and proportion of each behavior category were standardized. Then, the standardized frequency and proportion score per behavior per episode were averaged, after which the two standardized averages of each behavior were averaged across episodes. Thus, final standardized averages of toddlers' attention-focused regulation and caregiver-focused regulation were derived, that which took into consideration both frequency and percentage of time engaged in particular behaviors.

Additionally, a separate team of trained research assistants coded children's exhibited distress (e.g., negative facial expressions, negative vocalizations) during these episodes on a 5point scale (No Distress Shown to Distress Entire Episode), the score of which was subsequently utilized in the present study to account for children's level of distress in encountering the stimuli (Buss, 2011). Furthermore, I drew from the established literatures on the efficacious nature of these emotion regulation strategies (e.g., Buss \& Goldsmith, 1998; Calkins et al., 1999; Crockenberg \& Leerkes, 2004; Diener \& Mangelsdorf, 1999) and the stability of children's emotional traits shown in Lab-TAB episodes (Durbin, Hayden, Klein, \& Olino, 2007) to reinforce my operationalization of child emotion regulation as shown in these parent-child lab tasks. Episode distress ICCs ranged from .98-.99 $\left(M_{I C C}=.99\right)$.

Child anxiety symptomatology (Time 3). Mothers completed the 7-item Anxiety/Worry subscale $(\alpha=.69)$ and the 5-item Inhibition to Novelty subscale $(\alpha=.85)$ of the 126 -item InfantToddler Social and Emotional Assessment (ITSEA; Carter, Briggs-Gowan, Jones, \& Little, 2003) to provide a report of their children's anxiety symptomatology as an outcome at T3. Using a 3-point scale $(0=$ Not true/Rarely to $2=$ Very true/Often $)$, mothers reported how well/often the statements described their child in the past month. Example items include '[my child] seems nervous, tense, or fearful' (Anxiety/Worry subscale) and '[my child] takes a while to feel comfortable in new places' (Inhibition to Novelty subscale). In past studies, the ITSEA has demonstrated acceptable to excellent test-retest and internal reliability, as well as construct validity (e.g., with respect to other measures of child behavioral functioning and symptoms), and 
it is appropriate for children ages 1-4 years old (Carter \& Briggs-Gowan, 2006; Carter et al., 2003; Mian et al., 2011).

Additionally, mothers completed the 5-item Generalized Anxiety subscale $(\alpha=.77)$ and the 6-item Social Anxiety subscale $(\alpha=.85)$ of the 34-item Preschool Anxiety Scale (PAS; Spence, Rapee, McDonald, \& Ingram, 2001) which assessed age-appropriate symptoms of generalized anxiety and social anxiety, respectively. Mothers responded to items on a 5-point scale ( $0=$ Not true at all to $4=$ Very often true), with respect to how well the statements described their child, and example items include '[my child] has difficulty stopping him/herself from worrying' (Generalized Anxiety subscale) and '[my child] is afraid of meeting or talking to unfamiliar people' (Social Anxiety subscale). The PAS is appropriate for preschool-age children and has demonstrated good test-retest and internal reliability, in addition to construct validity with respect to other measures of anxiety symptomatology (Spence et al., 2001). Overall mean composite scores were derived from the four ITSEA and PAS subscales to create a latent construct representation of children's T3 anxiety symptomatology.

\section{Data Analytic Strategy}

All variables were subject to univariate data screening, and composites were transformed if skew exceeded $|2.00|$ and/or kurtosis exceeded |10.00|. As missing data was a concern because of the nature of the current study's longitudinal sample, it was determined if there was missingness among primary variables and if sample subpopulations differing on missingness had any differences in their scores on primary variables. Little's missing completely at random (MCAR) test was run. For preliminary analyses, bivariate correlations were utilized to assess associations between study variables, as well as family demographic variables (e.g., child gender, family socioeconomic status) and variables of interest to determine possible covariates.

The measurement and structural equation models were run and analyzed through Mplus Version 7.3 (Muthén \& Muthén, 2012). The Mplus application was chosen for analyses because of its simultaneous measurement of individual paths and indirect effects in the context of a single model. Moreover, it was utilized for its methods of handling missing data and its capabilities for assessing and comparing model fit. Regarding the former point, for all analyses henceforth, full information maximum likelihood estimation (Enders \& Bandalos, 2001; Graham, 2009) was used in Mplus to analyze and estimate patterns in missing data. A confirmatory factor analysis was run to determine if the child anxiety latent variable was satisfactory. Then, four structural 
equation models were estimated to assess model fit, relations among primary variables (Aim 1), and indirect effects among variables (Aim 2). Models varied by T2 mother emotion socialization (either supportive or unsupportive) and T2 child emotion regulation (either attention- or caregiver-focused), for a total of four models (see Figure 1 and 2 for the hypothesized conceptual model). All model variables were continuous and manifest, with the exception of T3 child anxiety, which was continuous and latent. Specifically, the ITSEA and PAS child anxiety scales were modeled as predicted from a single latent variable to provide a robust child anxiety composite. T2 observed child distress was entered as a covariate for relevant primary variables (i.e., T2 emotion socialization, T2 child emotion regulation, T3 child anxiety) in all models. Of note, any statistically significant paths accounted for all other paths to that particular dependent variable in the model. For example, if the association between T2 mother emotion socialization and T3 child anxiety was statistically significant at a .05 alpha level, then that association existed above and beyond all other modeled relations to child anxiety (e.g., the relation between child emotion regulation and child anxiety).

In analyses, T1 maternal emotion dysregulation and child observed distress during episodes at T2 were the only exogenous variables. Endogenous variables included maternal emotion socialization, child emotion regulation, and T3 child anxiety. Thus, there were a total of 8 observed variables and 1 latent variable. As the number of parameters in these models was less than the number of manifest variable variances and covariances, the models were over-identified, allowing for positive degrees of freedom $(d f=12)$ and the possibility of model rejection.

In each of the four structural equation models (varying on mother emotion socialization and child emotion regulation), hypotheses were tested through a single model. I simultaneously tested model fit, associations between variables (Aim 1), and indirect effects between variables (Aim 2). I examined indices of model fit, including statistics assessing statistical fit (chi square), absolute fit (root mean square error approximation [RMSEA], standardized root mean square residual [SRMR]), and relative fit (TLI, CFI), as consistent with researcher suggestions (Byrne, 2013; Hu \& Bentler, 1999; Kline, 2011). AIC and sample-size adjusted BIC were also reported. Non-significant chi square values, RMSEA values $\leq .08$, SRMR values $\leq .08$, CFI values $\geq .90$, and TLI values $\geq .95$ indicated minimally acceptable model fit (Hu \& Bentler, 1999). Regarding Aim 1, path coefficients were considered statistically significant at $p \leq .05$ and marginally statistically significant at $p<.10$. For $\operatorname{Aim} 2$, the same standards were applied, and indirect 
effects were estimated using 10,000 bootstrap confidence intervals, as recommended in the literature (Hayes, 2017).

\section{Results}

\section{Preliminary Analyses}

Missing data. Missing data existed for all primary variables. Thirty-eight participants (21.7\%) did not have maternal emotion dysregulation at T1, either because they began participation at T2 $(12 \%)$ or T3 $(5.1 \%)$ or because they participated in T1 prior to the addition of the DERS measure (4.6\%). Sixty-five mothers (37.1\%) did not complete the T2 CTNES to indicate supportive and unsupportive emotion responses. Forty-nine participants (28.0\%) did not have the observational measure of child emotion regulation behaviors, either because they moved out of town and only completed mailed questionnaires, there was experimenter error or technical difficulties in recording the video, or rarely, the child refused to participate in the task. Fifty-four participants (30.9\%) did not have the distress coding for similar reasons. Eighty-one participants (46.3\%) did not complete the ITSEA and ninety-one participants $(52.0 \%)$ did not complete the PAS at T3, because of attrition and ongoing data collection in the larger study and some participants completing other parts of the visit but not this measure. Taken together, $37.94 \%$ of primary variable values were missing.

Mothers who began participating at T2 or T3 endorsed more unsupportive emotion socialization $(M=2.95, S D=0.69, t[108]=2.12, p=.037$, Cohen's $d=0.59)$ than mothers who began their participation at T1 $(M=2.54, S D=0.78)$. Mothers who began participating at later time-points also had children who displayed fewer caregiver-focused emotion regulation behaviors $(M=-0.28, S D=0.40, t[62.18]=-2.69, p=.009$, Cohen's $d=0.49)$, relative to children who began participating at T1 $(M=0.05, S D=0.85)$. However, these families did not differ on education level, family income, number of children, or any other primary study variables.

Little's missing completely at random (MCAR) test indicated that the pattern of missingness in the data deviated from a MCAR pattern $\left(\chi^{2}[290]=353.60, p=.006\right)$. Full information maximum likelihood was used to handle missing data, as has been recommended in the literature (Graham, 2009; Graham, Cumsille, \& Shevock, 2012).

Descriptive statistics and bivariate associations. Descriptive statistics for primary variables (prior to transformations) are presented in Table 1. All variables showed moderate 
adherence to a normal distribution, such that skew was $<|2.00|$ and kurtosis was $<|2.00|$, with minor exceptions. Kurtosis was higher for T2 observed caregiver-focused behaviors (kurtosis = 6.47); however, this score was not transformed to accommodate a priori standards and retain score interpretability. Child generalized anxiety (PAS) and social anxiety (PAS) data had kurtoses of 6.38 and 3.38 and were square root transformed to allow for greater adherence to a normal distribution.

Bivariate associations among primary variables and demographics are reported in Table 2. Given high correlation between the variables $(r=.60, p<.001)$, maternal education (in years) and family annual income were z-scored and then averaged to create a composite of socioeconomic status. Maternal emotion dysregulation was positively related to unsupportive, but not supportive, emotion socialization $(r=.36, p=.001){ }^{2}$ Interestingly, mothers' supportive and unsupportive emotion responses at T2 were not correlated at a bivariate level $(r=.02, p=$ .828). This lack of association corroborates the conceptualization of supportive and unsupportive emotions socialization as distinct constructs. After standardizing and averaging across frequencies and proportions, children's T2 caregiver-focused regulation behaviors were positively associated across episode $(r=.38, p<.001)$, suggesting some stability across contexts, whereas their "clown" and "spider" attention-focused regulation attempts were not correlated $(r$ $=.12, p=.891)$. Further, for the "clown" episode only, children who displayed greater caregiverfocused regulation also had greater attention-focused regulation $(r=.27, p=.002)$. When emotion regulation behaviors were collapsed across episode, the relation between caregiverfocused and attention-focused regulation was no longer significant $(r=.08, p=.364)$. Observed child distress at T2 was not related to the emotion regulation behavior categories within or collapsed across episodes ( $r \mathrm{~s}=-.01-.02, p s=.126-.926)$, with the exception of caregiver-focused regulation during the "clown" episode which was marginally associated with greater observed child distress $(r=.15, p=.098){ }^{3}$

\footnotetext{
${ }^{2}$ One additional set of correlations of interest was run to determine if the association between maternal emotion dysregulation and unsupportive emotion socialization was largely accounted for by mothers' distress reactions to their children's emotions. Examining the individual unsupportive emotion socialization strategies revealed that maternal emotion dysregulation was significantly related to distress reactions $(r=.42, p<.001)$ and punitive responses $(r=.31, p=.003)$, but not minimization responses $(r=.11, p=.330)$. A composite of punitive and minimization responses (without distress reactions) remained significantly associated with maternal emotion dysregulation $(r=.22, p=.040)$.

${ }^{3}$ To determine if the "spider" context was indeed more distressing than the "clown" context, a t-test was run, revealing that there was a significant difference in mean scores across the episodes. That is, the mean level of distress exhibited by children in the "spider" episode $(M=1.79, S D=1.06)$ was greater than that of children in the
} 


\section{Measurement Model of Child Anxiety}

All four indices of T3 child anxiety symptoms were positively related $(r s=.26-.68, p s<$ .001 ), with the highest association observed between ITSEA inhibition to novelty and PAS social anxiety. A confirmatory factor analysis was run in which the four anxiety subscales (ITSEA anxiety/worry, ITSEA inhibition to novelty, PAS generalized anxiety, PAS social anxiety) were made to load onto a single factor, henceforth referred to as "child anxiety." In this measurement model, primary variables of the proposed structural equation model were also entered to allow for correlations between variables. To set the scale for latent variables, the marker variable technique was used, in which the scale of one of the factor indicators was fixed to one. The measurement model's fit mostly ranged from poor to mediocre, $\chi^{2}(d f=23, N=175)=56.26, p$ $=.0001 ; \mathrm{AIC}=1662.62$, sample-size adjusted $\mathrm{BIC}=1662.54 ; \mathrm{RMSEA}=0.091(90 \% \mathrm{CI}[0.061$, $0.121]) ; \mathrm{SRMR}=0.062 ; \mathrm{CFI}=0.801, \mathrm{TLI}=0.611$. However, the model modification indices (set to display at $\geq 10.0$ ) suggested that the model fit statistics may improve with the addition of several correlations between the factor error terms. Specifically, additional associations between the error terms of ITSEA anxiety/worry and PAS general anxiety $(\mathrm{MI}=25.67)$, ITSEA inhibition to novelty and PAS social anxiety $(\mathrm{MI}=25.04)$, ITSEA inhibition to novelty and PAS general anxiety $(\mathrm{MI}=15.41)$, and ITSEA anxiety/worry and PAS social anxiety $(\mathrm{MI}=11.24)$ were recommended. To maintain parsimony, proceed sequentially, and alter the model in line with theory, only the two modification indices with the highest values (e.g., ITSEA anxiety/worry and PAS general anxiety, ITSEA inhibition to novelty and PAS social anxiety) were added to the model before rerunning the fit statistics. See Figure 3 for the final measurement model. Model fit statistics substantially improved after adding these correlations into the model. Specifically, the measurement model's fit was mostly close (with only TLI suggesting acceptable fit), $\chi^{2}$ ( $d f=21$, $N=175)=26.32, p=0.1945 ;$ AIC $=1636.68$, sample-size adjusted $\mathrm{BIC}=1636.59 ;$ RMSEA $=$ 0.038 (90\% CI [ 0.00, 0.078]); SRMR $=0.049 ; \mathrm{CFI}=0.968, \mathrm{TLI}=0.932$. Because no other modification indices had values $\geq 10.0$ and this model fit the data better than that without the additional correlations, this model was retained and its factor structure was explored. All indices positively and significantly loaded onto the "child anxiety" latent construct ( $p s \leq .001)$, and they ranged from moderate to large in size (standardized loadings $=0.45-0.80$ ). Together, the factors

"clown" episode $(M=1.37, S D=0.74), t(114)=-3.93, p<.001$. This difference was consistent with past research and present hypotheses. 
accounted for $63.3 \%$ of the variance in the "child anxiety" latent variable $\left(R^{2} \mathrm{~s}=20.1-63.3 \%\right.$ in stepwise addition of factors), with ITSEA anxiety/worry $(p=.015)$, PAS general anxiety $(p=$ $.004)$, and PAS social anxiety $(p=.001)$ all contributing to significantly better models at each step.

\section{Primary Structural Equation Models}

Once the structure of the latent factor was determined to be acceptable, four structural equation models were run to test main hypotheses. See Figures 1 and 2 for conceptual models of main analyses. Specifically, the models varied on T2 maternal emotion socialization type (supportive or unsupportive) and T2 child emotion regulation behavior category (caregiver- or attention-focused). All other variables were consistent throughout the four models, including T2 observed child distress, which was entered as a covariate predicting primary variables. In the sections below, only paths outside of the measurement model of child anxiety will be noted.

Supportive emotion socialization and caregiver-focused emotion regulation. This model had close fit, $\chi^{2}(d f=12, N=175)=13.60, p=0.327$; AIC $=1124.62$, sample-size adjusted $\mathrm{BIC}=1124.56 ; \mathrm{RMSEA}=0.028(90 \% \mathrm{CI}[0.00,0.084]) ; \mathrm{SRMR}=0.038 ; \mathrm{CFI}=0.989$, TLI $=0.976$. Here, two paths were statistically or marginally significant (Aim 1, see Figure 4).

Specifically, T1 maternal emotion dysregulation was positively associated with T3 child anxiety $(b=0.17, S E=0.07, p=.008)$, above and beyond T2 maternal emotion socialization, child distress, and child caregiver-focused emotion regulation. Additionally, child distress was marginally positively associated with supportive emotion socialization at $\mathrm{T} 2(b=0.23, S E=$ $0.13, p=.067$ ), controlling for T1 maternal emotion dysregulation. All other pathways were not significant at a .05 alpha level. All indirect effects (Aim 2) were non-significant.

\section{Supportive emotion socialization and attention-focused emotion regulation. The} second model mostly had fit ranging from acceptable to close (with only the TLI suggesting mediocre fit $), \chi^{2}(d f=12, N=175)=21.50, p=0.044$; AIC $=1084.81$, sample-size adjusted BIC $=1084.75 ; \mathrm{RMSEA}=0.067$ (90\% CI [ 0.011, 0.112]); $\mathrm{SRMR}=0.047 ; \mathrm{CFI}=0.939, \mathrm{TLI}=$ 0.863. In this model, three paths were significant or marginally significant (Aim 1, see Figure 5). First, the same positive relation between T1 maternal emotion dysregulation and T3 child anxiety present in the first model emerged ( $b=0.15, S E=0.07, p=.023)$, as well as the same marginal relation between T2 child distress and supportive emotion socialization $(b=0.25, S E=0.13, p=$ .052). Additionally, however, there was a positive relation between T1 maternal emotion 
dysregulation and T2 child attention-focused regulation $(b=0.30, S E=0.13, p=.022)$ that existed over and above the effects of T2 maternal emotion socialization and T2 child distress on $\mathrm{T} 2$ child attention-focused regulation. The remaining pathways and all indirect effects were nonsignificant (Aim 1, 2).

\section{Unsupportive emotion socialization and caregiver-focused emotion regulation. Fit}

statistics indicated that the third model had close fit, $\chi^{2}(d f=12, N=175)=12.75, p=0.388$; $\mathrm{AIC}=1080.33$, sample-size adjusted $\mathrm{BIC}=1080.27 ; \mathrm{RMSEA}=0.019(90 \% \mathrm{CI}[0.00,0.081]) ;$ $\mathrm{SRMR}=0.038 ; \mathrm{CFI}=0.995, \mathrm{TLI}=0.990$. In this model, several paths were statistically significant (Aim 1, see Figure 6). That is, greater maternal emotion dysregulation at T1 was associated with both more unsupportive emotion socialization at T2 $(b=0.55, S E=0.15, p<$ $.001)$ and (marginally) with greater child anxiety at T3 ( $b=0.13, S E=0.07, p=.053)$, controlling for T2 child distress. Additionally, T1 maternal emotion dysregulation (marginally; $b$ $=-0.30, S E=0.17, p=.079)$ and T2 maternal emotion socialization $(b=0.22, S E=0.11, p=$ .043 ) both predicted T2 child caregiver-focused regulation, such that when mothers had less emotion dysregulation or engaged in more unsupportive emotion socialization, they had toddlers who engaged in more caregiver-focused emotion regulation attempts. Importantly, these effects were present over and above the effect of one another, as well as T2 child distress. Remaining pathways were not significant, as well as the indirect effects, with one exception (Aim 2). There was a marginally significant indirect effect from T1 maternal emotion dysregulation to T2 child caregiver-focused emotion regulation through T2 unsupportive emotion socialization $(a b=0.12$, $S E=0.07, p=.089,95 \% \mathrm{CI}=[0.010, .290])$. Thus, greater maternal emotion dysregulation appeared to predict more unsupportive emotion socialization practices, which in turn contributed to more caregiver-focused emotion regulation behaviors.

Unsupportive emotion socialization and attention-focused emotion regulation. The final model had fit ranging from mediocre to close (only TLI suggesting mediocre fit), $\chi^{2}$ ( $d f=$ $12, N=175)=21.57, p=0.043 ;$ AIC $=1043.28$, sample-size adjusted BIC $=1043.22 ;$ RMSEA $=0.068(90 \%$ CI $[0.012,0.113]) ; \mathrm{SRMR}=0.048 ; \mathrm{CFI}=0.942, \mathrm{TLI}=0.871$. In this model, one path was statistically significant (Aim 1, see Figure 7). Specifically, T1 maternal emotion dysregulation was strongly and positively associated with T2 unsupportive emotion socialization $(b=0.55, S E=0.17, p=.001)$. All remaining pathways and indirect effects were non-significant (Aim 1, 2). 


\section{Post-Hoc Models}

Models without $\mathbf{T} 2$ child distress as a covariate. The four primary models were run without entering $\mathrm{T} 2$ child distress as a covariate to determine if fit statistics and relations among variables would improve. For three of the models (i.e., supportive emotion socialization and caregiver-focused behaviors, supportive emotion socialization and attention-focused behaviors, unsupportive emotion socialization and attention-focused behaviors), fit statistics emerged as similar or slightly improved, main effects were similar or slightly worse, and no new indirect effects were found. In the model with unsupportive emotion socialization and caregiver-focused behaviors, the fit statistics worsened and the link between T1 maternal emotion dysregulation and T3 child anxiety dropped when T2 child distress was removed as a covariate.

\section{Models with T2 child distress as a moderator on path between T2 child emotion} regulation behavior and $\mathbf{T} 3$ child anxiety. It is possible that the relations between child emotion regulation behavior (i.e., caregiver- or attention-focused behaviors) and child anxiety may depend on the level of distress that the child was showing in the behavioral episode in which child emotion regulation behaviors were coded. Thus, post-hoc models were run to determine if $\mathrm{T} 2$ child distress moderated the association between $\mathrm{T} 2$ child emotion regulation behavior and T3 child anxiety. No interaction terms were significant in any of the models, so simple slopes were not probed.

\section{Models with emotion regulation behaviors separated by context. Eight structural} equation models were run to assess if differential relations emerged when examining T2 child emotion regulation behaviors per context (i.e., "spider" or “clown" episode). When running separate models per context for supportive emotion socialization and caregiver-focused regulatory behaviors, fit statistics were slightly worse or comparable, and similar paths were observed in both models, with two exceptions. In the "spider" context only, less T2 caregiverfocused emotion regulation $(b=-0.07, S E=0.03, p=.015)$ and greater distress (marginally; $b=$ $0.08, S E=0.05, p=.084$ ) additionally predicted greater T3 child anxiety. Thus, it appears that these effects were washed out in the larger, collapsed model.

For the two models examining supportive emotion socialization and attention-focused regulation behaviors per episode, some fit statistics within each model improved while others worsened. In both models, similar effects were observed, with one minor exception. In the "clown" episode model only, T2 child distress significantly predicted T2 supportive emotion 
socialization $(b=0.25, S E=0.13, p=.049)$, suggesting that the "clown" episode may be carrying the marginal effect observed in the corresponding primary model tested.

In the models assessing unsupportive emotion socialization and child caregiver-focused regulatory behaviors, there remained a positive relation between $\mathrm{T} 1$ maternal emotion dysregulation and both T2 unsupportive emotion socialization and T3 child anxiety. However, the two models varied in other ways. When examining the "clown" episode only, fit statistics were slightly worse than in the collapsed model and the effects of T1 maternal emotion dysregulation and T2 unsupportive emotion socialization on T2 child caregiver-focused behaviors were no longer statistically significant. Additionally, T2 child distress no longer predicted T3 child anxiety. Also, in this model, but not in the primary model, T2 child distress (marginally) positively predicted T2 caregiver-focused behaviors in the "clown" episode $(b=$ $0.20, S E=0.12, p=.095)$, suggesting that the main model had washed out the effect observed in this particular episode.

Regarding the model focused on the "spider" episode (see Figure 8), fit tended to improve and T1 maternal emotion dysregulation and T2 unsupportive emotion socialization predicted caregiver-focused behaviors, similarly to the primary model. Other similar relations to the main model were observed. An additional negative relation between T2 caregiver-focused behaviors in the "spider" episode and T3 child anxiety was also observed ( $b=-0.08, b=0.03, p$ $=.007)$. Moreover, the same marginally significant indirect effect emerged in the "spider" context, but not the "clown" context. Similar to that observed in the primary model, T1 maternal emotion dysregulation predicted more T2 caregiver-focused behaviors in the "spider" episode through mothers' greater T2 unsupportive emotion socialization $(a b=0.14, S E=0.09, p=.091$, $95 \% \mathrm{CI}=[.008, .357])$.

In the two models examining unsupportive emotion socialization and attention-focused behaviors per context, fit statistics within both models were mixed in improvement and worsening, and the same association between T1 maternal emotion dysregulation and T2 unsupportive emotion socialization was observed. Additionally, in both contexts, the same relation between T1 maternal emotion dysregulation and T3 child anxiety emerged, although it was marginal in the "clown" episode $(b=0.143, S E=0.07, p=.051)$ and significant in the "spider" episode $(b=0.14, S E=0.07, p=.044)$. Further, in the "clown" episode model only, T1 maternal emotion dysregulation was also positively and strongly related to child attention- 
regulation behaviors $(b=0.59, S E=0.20, p=.004)$. It appears that this effect was washed out in the larger model that collapsed across episodes.

Models with gender as a grouping variable. A multigroup structural equation modeling approach was utilized to determine if the four primary models varied overall for boys versus girls. Specifically, for each of the primary models, free and constrained models (based on gender

group) were estimated, and the differences between chi square values were calculated (with change in degrees of freedom between the models acting as degrees of freedom for the change test). These differences were not statistically different on the basis of gender in any of the models. Thus, models fit equally well for boys and girls.

\section{Discussion}

This study examined how maternal and child-level emotion constructs may longitudinally predict one another and child anxiety symptomatology. Specifically, models were tested in which maternal emotion dysregulation, maternal emotion socialization, child distress, and child emotion regulation behaviors all predicted child anxiety symptoms.

Because child anxiety is highly prevalent and its mechanistic underpinnings not yet thoroughly understood (Chavira et al., 2004a), it is critical to identify emotion processes within the family context that may inform prevention and treatment efforts. This research builds on prior work by (a) using integrated models to assess the cumulative effect of these emotion characteristics and practices on one another and child anxiety, (b) focusing on processes ongoing early in childhood (child ages 2-4 years), and (c) examining these linkages across three timepoints. Results indicated that models tended to fit the data well, and that individual path coefficients differed across models depending on maternal emotion socialization methods (i.e., supportive or unsupportive) and child emotion regulation (i.e., caregiver-focused or attentionfocused). Bivariate correlations among variables and main patterns observed across the models, as well as those unique to particular models, are discussed below.

\section{Bivariate Correlations}

Preliminary examination of bivariate correlations among primary study variables revealed several associations, though they were fewer in number than anticipated and were sometimes in an unexpected direction. Notably, maternal supportive emotion responses and unsupportive emotion responses were not related at a bivariate level, lending further support to past studies suggesting that the two constructs are conceptually distinct (e.g., Fabes et al., 1990; 
Klimes-Dougan et al., 2007). That is, the extent to which mothers engage in supportive responses to their child's emotion displays does not predict the amount of unsupportive reactions that they will also provide. Additionally, children's caregiver-focused emotion regulation behaviors, but not their attention-focused emotion regulation behaviors, were related across "clown" and “spider" episode contexts. These findings may suggest that caregiver-focused emotion regulation attempts may be more domain-general, with children engaging in similar amounts across a variety of contexts. Alternatively, frequency of and proportion of time spent engaging in attention-shifting behaviors may more directly depend on the nature of the novel stimulus. Such results are also interesting when considering that in this particular sample, children tended to engage in more caregiver-focused emotion regulation attempts, in comparison to attentionshifting behaviors. Moreover, the types of child emotion regulation behaviors were (positively) related in the "clown," but not "spider" context. This discrepancy between contexts may be partially due to the relatively short duration of the "spider" episode ( $\sim 1$ minute) versus the longer length of the "clown" episode ( $\sim 5$ minutes), such that children may not have as much opportunity to engage in both behaviors. Alternatively, it may be that children show a preference for one emotion regulation behavior, rather than a combination of multiple behaviors, when encountering more distressing stimuli. Of final note, child distress during behavioral episodes tended to not be related to child emotion regulation behaviors, somewhat surprisingly. Future research may benefit from clarifying if there may be a curvilinear relation between distress and emotion regulation attempts. Perhaps well-regulated and highly-distressed children may both be engaging in high amounts of regulatory behaviors, with only the well-regulated children succeeding in alleviating distress.

\section{Main and Post-Hoc Structural Equation Models}

Indirect effects and cross-cutting associations. Several main themes emerged when examining the primary and post-hoc structural equation models. First, none of the single and serial mediation models run were statistically significant, with one exception. Regarding the one marginally significant effect, greater maternal emotion dysregulation predicted greater unsupportive emotion socialization, which in turn related to children's greater caregiver-focused emotion regulation behaviors. Although this mediation was hypothesized, it was only partially in the expected direction. The direct association between maternal emotion dysregulation and child caregiver-focused behaviors was negative, suggesting that mothers who are more dysregulated in 
their emotion management have children who are less likely to seek out their caregiver during times of distress. This directionality was hypothesized and is supported by recent theory and research evidencing a transmission of congruent emotion regulation tendencies from parents to children (e.g., Bariola et al., 2011; Morelen et al., 2016). More generally, it may indicate that children with dysregulated mothers may not view their mothers as reliable sources of external regulation. Interestingly, however, examination of the indirect effect revealed a different perspective on this transmission of emotion management abilities. Here, maternal emotion dysregulation and unsupportive emotion socialization were strongly related in the hypothesized positive direction; however, mothers' more frequent unsupportive responses predicted children's greater use of caregiver-focused strategies. On the one hand, this finding lends support to theory that the transmission of emotion regulation operates through parental emotion socialization practices (e.g., Morris et al., 2007). On the other hand, this indirect effect somewhat contradicts the main effect observed between maternal emotion dysregulation and child caregiver-focused regulation, instead suggesting that when mothers' unsupportive emotion responses are a part of the model, more unsupportive parenting is associated with a greater reliance on one's caregiver. Albeit contrary to hypotheses, this series of associations carries several possible interpretations. Foremost, it may be that when learning from a mother who is emotionally dysregulated and responds unsupportively to emotion displays, children may struggle to develop early means to effectively manage their emotions. As such, they may seek out and rely more on external emotion regulation from their mother (e.g., via caregiver-focused behaviors) at a heightened rate, consistent with studies showing a link between child distress and mother-seeking behaviors (Buss et al., 2008). Over time, these actions may foster a cycle in which emotionally dysregulated mothers have children who struggle to manage emotions on their own, consequently depending on their mothers to aid in regulation, which may in turn foster more unsupportive parenting behaviors. Along these lines, there is some evidence to support the notion that children showing more distress or more emotion regulation attempts may actually elicit more unsupportive responses from their parents. For instance, Luebbe and colleagues (2011) found that toddlers' greater internalizing behaviors were associated with mothers' more frequent engagement in unsupportive emotion socialization. Additionally, Premo and Kiel (2014) found that young children who showed more attention-focused regulation in a high-threat context had mothers who engaged in more unsupportive emotion socialization. Alternatively, because both 
emotion socialization and child emotion regulation were measured at the same time-point, it may be the case that children who elicit high levels of attention from their mothers - from proximityseeking and/or looks towards their mother-may naturally receive more unsupportive responses. This greater receipt of punishing, minimizing, and distressed responses may generally correspond to frequent child attention-seeking behavior or may be a byproduct of the sheer frequency of child attempts to elicit a maternal response. For instance, if a high attention-seeking child elicits maternal involvement numerous times, perhaps the mother is highly supportive half of those times but begins responding more negatively when attention-seeking behavior continues past that point. These mothers would be categorized as more frequently engaging in unsupportive emotion responses, despite their also frequent tendency to respond supportively, merely because of the sheer amount of eliciting events by their child. This explanation is supported by the nearzero bivariate correlation between supportive and unsupportive emotion responses. Of final note, it is important to also acknowledge that in this particular mediation model, both the mediator and the outcome variable were measured at the same time-point, thereby limiting inferences about directionality and causality in this model.

When considering why no other single or serial mediation models emerged as significant, it is important to note that the multimethod nature of this study likely decreased shared method variance, potentially making it more difficult to find relations between maternal report and observational measures. Indeed, it appears that in most models, the associations to and from the child emotion regulation behaviors were relatively weak. It is additionally possible that these emotion regulation behaviors may be too context- and age-specific to carry implications for mothers' earlier behaviors and children's subsequent anxiety. Perhaps more global measures of child emotion regulation or profiles of children's regulatory behaviors across contexts may provide a clearer snapshot of child emotion regulation functioning. Alternatively, perhaps there are other key moderators missing in these models that would produce contextualized relations between primary variables. More generally, too, the substantial 1-year period of time between each study time-point likely attenuated relations between variables, potentially because of competing processes among variables in or outside the model (Shrout \& Bolger, 2002). It is possible that a smaller time-course (e.g., 2-3 months) may have produced more indirect relations.

Beyond indirect effects, a variety of interesting patterns were also observed with respect to the individual paths. For one, in all four main models, maternal emotion dysregulation 
predicted greater child anxiety approximately two years later, although this effect was marginal in models with the unsupportive emotion socialization variable. Compellingly, this link existed over and above the effects of maternal emotion socialization, child episode distress, and child emotion regulation behaviors on child anxiety. Thus, although the extent to which mothers are dysregulated in their emotion management may indirectly contribute to child anxiety (e.g., through emotion socialization, child emotion), it appears that it also operates as a direct mechanism for child anxiety symptom development. Importantly, such maternal emotion dysregulation is likely to directly impact children at both a genetic and environmental level. This present finding is among the first to signal a persistent, direct linkage between these processes in early childhood, and future research may benefit from looking beyond the influence of specific parent psychopathology to additionally target more transdiagnostic factors (i.e., maternal emotion dysregulation) involved in child anxiety risk.

Themes in supportive emotion socialization models. Examination of models with the supportive emotion socialization composite revealed additional patterns in variable relations. Child distress was entered as a covariate in all models, such that it predicted maternal emotion socialization, child emotion regulation, and child anxiety so other primary associations may be interpreted as present "controlling for" child distress. Of note, in the supportive emotion socialization models only, greater child distress was marginally related to mothers' greater use of supportive emotion responses, over and above the effect of maternal emotion dysregulation. It may be that higher child distress (e.g., either observed distress or general internalizing symptomology) prompts more supportive (or minimally, more involved) parenting behaviors, as some studies have suggested (Buss et al., 2008; Luebbe et al., 2011). Alternatively, given that these two variables were measured at the same time-point and causality cannot be inferred, mothers' supportive emotion responses may actually elicit children's greater distress. Although this notion may seem counterintuitive at first glance, many researchers do theorize that emotion displays are inherently functional and communicative (Campos, Mumme, Kermoian, \& Campos, 1994), and children receiving supportive responses may seek to maintain those responses by amplifying their level of distress. In contrast to this finding, in models including unsupportive emotion socialization, child distress did not relate to the extent to which mothers engaged in unsupportive emotion responses. 
Additionally, in the supportive emotion socialization model only (but not the unsupportive emotion socialization model), maternal emotion dysregulation predicted child attention-focused behaviors, such that mothers who were more dysregulated had children who later showed more looking-away behaviors when encountering novel stimuli. This finding may suggest that these behaviors may actually derive in part from parents' more negative emotionrelated characteristics. It is unclear the extent to which these relations may result from genetic versus environmental transmission of emotion regulation/dyrsegulation, although both have been evidenced by other studies (Buckholdt et al., 2014; Morelen et al., 2016; Ostlund et al., 2019). Notably, these child looking-away behaviors were unrelated to child distress; in fact, in all models, child emotion regulation behaviors did not correspond to level of child distress. This lack of relation may suggest that these putatively regulatory behaviors may not necessarily always occur when children are experiencing a high level of distress or be contingent with decreases in child distress. This is supported by the mixed body of research findings on the efficacy of these early-arising methods and their associations with subsequent symptom-based outcomes (e.g., Buss \& Goldsmith, 1998; Diener \& Mangelsdorf, 1999; In-Albon et al., 2010). This pattern is especially interesting when considering that in the model with unsupportive emotion socialization and caregiver-focused behaviors, maternal emotion dysregulation directly predicted fewer caregiver-focused behaviors. Taken together, these findings seem to indicate that children whose mothers are more emotionally dysregulated engage in more looking-away behaviors on their own but tend to rely less on their caregiver for external regulation. Indeed, there has been some past suggestion (e.g., from the extensive literature on attachment styles; see also Cassidy, 1994) that when mothers are distressed themselves or have difficulties managing emotions, children may tend to navigate novel situations more independently, whether that is beneficial or detrimental in the long-term.

Themes in unsupportive emotion socialization models. Some unique associations were observed in the structural equation models with unsupportive emotion socialization. For both models with different regulation types (i.e., caregiver-focused regulation, attention-focused regulation), there was a robust positive relation between maternal emotion dysregulation and unsupportive emotion responses. Recall that maternal emotion dysregulation did not relate to supportive responses. Perhaps unsupportive emotion responses are a more direct manifestation of maternal emotion dysregulation, with mothers' maladaptive tendencies to manage emotions 
more readily predicting their unsupportive parenting practices, rather than their supportive behaviors. Congruently, it seems that mothers may be showing varying levels of supportive emotion responses, regardless of the extent to which they are dysregulated emotionally. There is some precedent for this in the extant literature, which offers equivocal findings on the links between parental emotion dysregulation and emotion socialization practices (Morelen et al., 2016; Raval et al., 2018). Further, in both of these models, it remains unclear which responses to emotion displays (either supportive or unsupportive) are more important for child anxiety development, as maternal emotion socialization did not predict child anxiety in any of the main models when accounting for other predictors (i.e., maternal emotion dysregulation, child distress, child emotion regulation).

Additionally, the model with unsupportive emotion socialization and caregiver-focused regulation was the only one in which these two variables were related. Specifically, it appeared that greater unsupportive responses to emotions were associated with more caregiver-focused regulatory behavior, as has been discussed in the above sections. Moreover, this same model was the only one in which child distress directly (positively) predicted later child anxiety. Thus, once specific variance is accounted for (e.g., that of unsupportive emotion socialization and caregiverfocused behaviors), early behavioral manifestations of distress may be stable over time and predict later anxiety symptom development.

Contextualized post-hoc models. Four sets of post-hoc models were also run to determine if certain model changes would contextualize results. First, models without child episode distress entered as a covariate did not appear to fit better than models incorporating a measure of child distress, suggesting that the models with child distress predicting primary variables were appropriate. Second, models were run in which child distress was tested as a moderator of the path between child emotion regulation and later anxiety symptoms. It is possible that the immediate and long-term efficacy of a child's emotion regulation behaviors may depend on the level of distress that the child is experiencing when they implement said regulatory behaviors. However, this was not the case, as child distress did not emerge as a significant moderator on this path in any of the four tested models. Thus, it appeared that distress was appropriately conceptualized as a covariate on several of the primary paths, rather than being omitted or utilized as a moderator. 
Third, because contexts varying in level of threat may potentially elicit different levels of child emotion regulation behaviors, eight models were run to determine if path coefficients differed when separating out child emotion regulation behaviors by context (i.e., "spider" or "clown" episode). For the most part, models were highly similar to those observed when collapsing across contexts, with a few paths that emerged in one context but not another. Furthermore, one interesting finding emerged with respect to the association between child emotion regulation behaviors and subsequent anxiety symptoms. There was no relation between these variables in the four main structural equation models; however, for post-hoc models including caregiver-focused emotion regulation attempts in the "spider" context only, there was a negative relation between caregiver-focused regulation behaviors and child anxiety. This effect was marginal and statistically significant in the models with supportive and unsupportive emotion socialization for this context, respectively, and was in the predicted direction, with more caregiver-focused regulation attempts contributing to lower rates of child anxiety symptoms. Interestingly, it only emerged in the context hypothesized to elicit greater child distress, rather than the more medium-level threat-natured "clown" episode. Perhaps the efficacy of and longerterm outcomes associated with caregiver-focused emotion regulation depends on the extent to which these novel events are distressing. That is, there is some evidence to suggest that children who show high levels of fear in less threatening contexts may be at greater risk for anxiety development (e.g., see Buss, 2011), so perhaps it also stands that children who only engage in caregiver-seeking behaviors in high-threat situations may be making more appropriate use of their emotion regulation behaviors and may be at lower risk for anxiety symptoms.

Fourth and finally, primary models were run using a multigroup structural equation modeling approach to determine if the models significantly varied for girls versus boys. Findings suggested that models did not differ depending on gender and that observed effects as a whole tended to be similar across boys and girls. There is a precedent for gender differences in (a) the ways that parents socialize emotions (particularly with respect to anger and sadness; e.g., Cassano \& Zeman, 2010; Garside \& Klimes-Dougan, 2002) and child anxiety symptoms (Bender, Reinholdt-Dunne, Esbjørn, \& Pons, 2012). However, it is possible that these variablelevel gender differences do not readily translate into separate trajectories of risk for boys and girls. That is, maternal emotion dysregulation and pertinent family emotion processes may predict child anxiety risk across child genders. 


\section{Limitations and Future Directions}

The study was strengthened by its usage of multiple measures (including second-bysecond observational coding), its consideration of multiple emotion processes, its incorporation of a latent measure of child anxiety, and its longitudinal nature. Still, there exist several key study limitations and many future directions ripe for investigation. First, baseline parent emotion socialization practices and child anxiety symptoms were not accounted for in the models but may provide further clarity into change over time in these constructs. Second, while the current research utilized a composite of maternal emotion dysregulation, specific aspects of parental emotion dysregulation have received more attention in recent years and may carry more direct relevance to emotion socialization practices and children's own emotion regulation attempts. For instance, Duncan et al.'s (2009) "mindful parenting" framework includes an emphasis on increasing parents' emotional awareness in hopes of fostering more positive parent-child interactions. Other recent studies have focused on understanding the intergenerational transmission of particular emotion regulation strategies (e.g., suppressing emotional expressions; Bariola et al., 2012). Further, very little research has investigated how parents may manage their emotions within the family context, specifically, which conceivably may be more important for child emotional development than parent emotion regulation in non-parenting contexts. The field would benefit from reworked and/or novel measures that test context-specific emotion regulation strategies and abilities, as well as greater consideration of interacting environmental and genetic influences on children's emotion regulation development. Moreover, given the transdiagnostic nature and usage of the emotion dysregulation construct (Thompson, 2019), similar models of parental emotion dysregulation and pertinent family emotion processes should be tested with respect to the development of other forms of child psychopathology (e.g., child depressive symptoms).

Additionally, there are several ways in which measurement of parent emotion socialization may be improved. Our measures of supportive and unsupportive emotion socialization collapsed across different response strategies (e.g., punishment vs. minimization) and were not specific to any particular emotions (e.g., worry vs. anger). However, we do know that specific emotion response strategies are likely to vary by the type of discrete emotion expressed by the child (Garside \& Klimes-Dougan, 2002; O’Neal \& Magai, 2005), as well as the extent to which child emotion expressions are congruent with parents' gendered emotional 
expression expectations (Cassano \& Zeman, 2010). Perhaps, for instance, mothers' responses to their children's worry expressions may be particularly salient to children's anxiety development. Also, do parental emotion responses look different in public versus private settings? Future models may additionally benefit from inclusion of both supportive and unsupportive emotion socialization constructs so their relative contributions to child emotion regulation and anxiety may be better elucidated.

Regarding children's emotion regulation, it remains unclear if these early-arising behaviors are truly indicative of children's emotion regulation attempts and if they are deleterious or beneficial for child anxiety symptoms. Perhaps greater examination of stability in these behaviors over time, as well as greater attention to the context in which they are displayed, may clarify these equivocal relations. Introduction of new concepts such as dysregulated fear, also known as child fear in low-threat contexts (Buss, 2011), may be a promising example of this context consideration. Additionally, other emotion regulation behaviors (e.g., self-soothing; Bridges \& Grolnick, 1995; Stifter \& Braungart, 1995) may also benefit from inclusion, single models may be run to incorporate multiple emotion regulation behavior types if appropriately powered, and researchers may consider accounting for a possible feedback loop in which child emotion regulation affects how parents respond to child emotions. There is a burgeoning area devoted to consideration of the latter child-elicited effects (e.g., Kiel \& Kalomiris, 2015; Premo $\&$ Kiel, 2014), and child emotion regulation is a process well-suited for such bidirectional effects.

Finally, there are several contextual factors that may contribute to different trajectories in these emotion processes and child anxiety over time. This study examined these processes in a sample that was moderately diverse in socioeconomic status but relatively homogenous in terms of racial and ethnic makeup. For one, because there is some suggestion that socioeconomic status may impact emotion socialization practices (Chaplin, Casey, Sinha, \& Mayes, 2010), family socioeconomic status should be more directly incorporated into models, perhaps as a moderator on paths between maternal emotion dysregulation and emotion socialization or between emotion socialization and child outcomes. Importantly, too, there is a burgeoning area of research devoted to understanding how emotion socialization may operate differently for families in non-white and/or non-American contexts. By way of example, some researchers have begun to study how parents respond to their children's emotions when emotion displays are brought on by acts of 
discrimination and racism, specifically (see also Dunbar, Leerkes, Coard, Supple, \& Calkins, 2017). Assessment of these "racialized" emotion socialization practices may offer unique insight into how emotion expression and regulation norms are taught to and internalized in children who may face greater adversity and threat and show greater opportunity for resilience processes (Miller \& MacIntosh, 1999). Other groups of researchers are also pioneering critical work on other culturally-sensitive and culturally-focused domains of emotion socialization (e.g., Perez Rivera \& Dunsmore, 2011; Raval et al., 2018). Lastly, post-hoc models did not find overall model differences across boys and girls, but future studies may benefit from more nuanced examination of specific paths in which gender may play a moderating role.

\section{Conclusions and Implications for Research and Clinical Practice}

The present study offered a unique contribution to the literature as a 3 time-point, multimethod, integrative model of family emotion processes (i.e., maternal and child emotion regulation, maternal emotion socialization) contributing to early childhood anxiety. Results lend partial support to extant theoretical models of family emotion processes (Eisenberg et al., 1998; Morris et al., 2007), as well as theories of child anxiety development in the family context (Bögels \& Phares, 2008; Murray et al., 2009). The current research supports theory that maternal emotion dysregulation contributes to children's anxiety development. To a lesser extent, this study provides mixed support for the potential role of maternal emotion socialization and child emotion regulation in child anxiety development. Future work should aim to more precisely delineate the developmental sequence of these family emotion processes, as well as the contexts in which they may be most relevant to child anxiety symptoms.

Clinically, results highlight the potential importance of targeting parents' emotion-related characteristics (e.g., their emotion dysregulation) and behaviors (e.g., their emotion socialization practices), as well as children's own emotion regulation abilities, as preventative and early interventions for buffering children against anxiety disorders and symptomatology. There already exists some evidence that transdiagnostic, emotion-focused intervention programs may be efficacious in ameliorating child internalizing symptomatology (e.g., Bilek \& EhrenreichMay, 2012; Ehrenreich-May \& Bilek, 2012; Wilamowska et al., 2010), as well as those more generally incorporating parents into treatment (Barrett, Dadds, et al., 1996; Dadds et al., 1999; Mendlowitz et al., 1999; Rapee, Kennedy, Ingram, Edwards, \& Sweeney, 2010; Shortt et al., 2001). Although intervention efforts aimed at changing parenting practices may foster changes in 
children's risk for and/or diagnosis of anxiety (Barrett, Dadds, \& Rapee, 1996; Dadds et al., 1999; Mendlowitz et al., 1999; Shortt, Barrett, \& Fox, 2001), such efforts may be shortsighted in that they may not substantially alter maladaptive parental beliefs or characteristics engendering these behaviors. As such, it may be important for interventions to focus on promoting parents' adaptive ways of managing emotions and supportive ways of responding to their children's emotions, as recently proposed by several researchers (Havighurst \& Kehoe, 2017; Maliken \& Katz, 2013). Thus, the present study generates early implications for our understanding of family emotion processes as they put children at risk for the development of anxiety, and future research is needed to better clarify preliminary models of these processes. 


\section{References}

Aldao, A., Nolen-Hoeksema, S., \& Schweizer, S. (2010). Emotion-regulation strategies across psychopathology: A meta-analytic review. Clinical Psychology Review, 30(2), 217-237. https://doi.org/10.1016/J.CPR.2009.11.004

Angold, A., Costello, E. J., \& Erkanli, A. (1999). Comorbidity. Journal of Child Psycholology and Psychiatry, 40(1), 57-87. https://doi.org/10.1111/1469-7610.00424

Are, F., \& Shaffer, A. (2016). Family emotion expressiveness mediates the relations between maternal emotion regulation and child emotion regulation. Child Psychiatry \& Human Development, 47(5), 708-715. https://doi.org/10.1007/s10578-015-0605-4

Bariola, E., Gullone, E., \& Hughes, E. K. (2011). Child and adolescent emotion regulation: The role of parental emotion regulation and expression. Clinical Child and Family Psychology Review, 14(2), 198-212. https://doi.org/10.1007/s10567-011-0092-5

Bariola, E., Hughes, E. K., \& Gullone, E. (2012). Relationships between parent and child emotion regulation strategy use: A brief report. Journal of Child and Family Studies, 21(3), 443-448. https://doi.org/10.1007/s10826-011-9497-5

Barker, E. D., Jaffee, S. R., Uher, R., \& Maughan, B. (2011). The contribution of prenatal and postnatal maternal anxiety and depression to child maladjustment. Depression and Anxiety, 28(8), 696-702. https://doi.org/10.1002/da.20856

Barlow, D. H. (2004). Anxiety and its disorders: The nature and treatment of anxiety and panic. https://doi.org/10.1176/appi.ajp.159.8.1453

Barrett, P. M., Dadds, M. R., \& Rapee, R. M. (1996). Family treatment of childhood anxiety: A controlled trial. Journal of Consulting and Clinical Psychology, 64(2), 333-342. https://doi.org/10.1037//0022-006X.64.2.333

Beidel, D. C., \& Turner, S. M. (1997). At risk for anxiety: I. Psychopathology in the offspring of anxious parents. Journal of the American Academy of Child \& Adolescent Psychiatry, 36(7), 918-924. https://doi.org/10.1097/00004583-199707000-00013

Bell-Dolan, D. J., Last, C. G., \& Strauss, C. C. (1990). Symptoms of anxiety disorders in normal children. Journal of the American Academy of Child and Adolescent Psychiatry, 29(5), 759-765. https://doi.org/10.1097/00004583-199009000-00014

Bender, P. K., Reinholdt-Dunne, M. L., Esbjørn, B. H., \& Pons, F. (2012). Emotion dysregulation and anxiety in children and adolescents: Gender differences. Personality and 
Individual Differences, 53(3), 284-288. https://doi.org/10.1016/J.PAID.2012.03.027

Berg-Nielsen, T. S., Vikan, A., \& Dahl, A. A. (2002). Parenting related to child and parental psychopathology: A descriptive review of the literature. Clinical Child Psychology and Psychiatry, 7(4), 529-552. https://doi.org/10.1177/1359104502007004006

Bilek, E. L., \& Ehrenreich-May, J. (2012). An open trial investigation of a transdiagnostic group treatment for children with anxiety and depressive symptoms. Behavior Therapy, 43(4), 887-897. https://doi.org/10.1016/J.BETH.2012.04.007

Bögels, S. M., \& Brechman-Toussaint, M. L. (2006). Family issues in child anxiety: Attachment, family functioning, parental rearing and beliefs. Clinical Psychology Review, 26(7), 834856. https://doi.org/10.1016/J.CPR.2005.08.001

Bögels, S. M., \& Phares, V. (2008). Fathers' role in the etiology, prevention and treatment of child anxiety: A review and new model. Clinical Psychology Review, 28(4), 539-558. https://doi.org/10.1016/j.cpr.2007.07.011

Brand, A., \& Klimes-Dougan, B. (2010). Emotion socialization in adolescence: The roles of mothers and fathers. New Directions for Child and Adolescent Development, 2010(128), 85-100. https://doi.org/10.1002/cd.270

Bridges, L., \& Grolnick, W. (1995). The development of emotional self-regulation in infancy and early childhood. In Nancy Eisenberg (Ed.), Social Development (pp. 185-211). Thousand Oaks: Sage Publications.

Briggs-Gowan, M. J., Carter, A. S., Bosson-Heenan, J., Guyer, A. E., \& Horwitz, S. M. (2006). Are infant-toddler social-emotional and behavioral problems transient? Journal of the American Academy of Child and Adolescent Psychiatry, 45(7), 849-858. https://doi.org/10.1097/01.chi.0000220849.48650.59

Buckholdt, K. E., Parra, G. R., \& Jobe-Shields, L. (2014). Intergenerational transmission of emotion dysregulation through parental invalidation of emotions: Implications for adolescent internalizing and externalizing behaviors. Journal of Child and Family Studies, 23(2), 324-332. https://doi.org/10.1007/s10826-013-9768-4

Buss, K. A. (2011). Which fearful toddlers should we worry about? Context, fear regulation, and anxiety risk. Developmental Psychology, 47(3), 804-819. https://doi.org/10.1037/a0023227

Buss, K. A., Brooker, R. J., \& Leuty, M. (2008). Girls most of the time, boys some of the time: Gender differences in toddlers' use of maternal proximity and comfort seeking. Infancy, 
13(1), 1-29. https://doi.org/10.1080/15250000701779360

Buss, K. A., \& Goldsmith, H. H. (1998). Fear and anger regulation in infancy: Effects on the temporal dynamics of affective expression. Child Development, 69(2), 359-374. https://doi.org/10.1111/j.1467-8624.1998.tb06195.x

Buss, K. A., \& Goldsmith, H. H. (2000). Manual and normative data for the Laboratory Temperament Assessment Battery-Toddler Version.

Byrne, B. (2013). Structural equation modeling with Mplus: Basic concepts, applications, and programming. New York: Routledge.

Calkins, S. D. (1994). Origins and outcomes of individual differences in emotion regulation. Monographs of the Society for Research in Child Development, 59(2-3), 53-72. https://doi.org/10.2307/1166138

Calkins, S. D. (2007). The emergence of self-regulation: Biological and behavioral control mechanisms supporting toddler competencies. In C. Brownell \& C. Kopp (Eds.), Socioemotional development in the toddler years: Transitions and transformations (pp. 261-284). New York: Guilford Press.

Calkins, S. D., Gill, K. L., Johnson, M. C., \& Smith, C. L. (1999). Emotional reactivity and emotional regulation strategies as predictors of social behavior with peers during toddlerhood. Social Development, 8(3), 310-334. https://doi.org/10.1111/1467-9507.00098

Calkins, S. D., \& Hill, A. (2007). Caregiver influences on emerging emotion regulation: Biological and environmental transactions in early development. In J. J. Gross (Ed.), Handbook of emotion regulation (pp. 229-248). New York: Guilford Press.

Calkins, S. D., \& Johnson, M. C. (1998). Toddler regulation of distress to frustrating events: Temperamental and maternal correlates. Infant Behavior and Development, 21(3), 379-395. https://doi.org/10.1016/S0163-6383(98)90015-7

Calkins, S. D., Smith, C. L., Gill, K. L., \& Johnson, M. C. (1998). Maternal interactive style across contexts: Relations to emotional, behavioral and physiological regulation during toddlerhood. Social Development, 7(3), 350-369. https://doi.org/10.1111/1467-9507.00072

Campos, J. J., Mumme, D. L., Kermoian, R., \& Campos, R. G. (1994). A functionalist perspective on the nature of emotion. In N. A. Fox (Ed.), The development of emotion regulation: Biological and behavioral considerations. Chicago, Illinois: University of Chicago Press. 
Carter, A. S., \& Briggs-Gowan, M. J. (2006). ITSEA: Infant-Toddler Social and Emotional Assessment examiner's manual. San Antonio: PsychCorp.

Carter, A. S., Briggs-Gowan, M. J., Jones, S. M., \& Little, T. D. (2003). The Infant-Toddler Social and Emotional Assessment (ITSEA): Factor structure, reliability, and validity. Journal of Abnormal Child Psychology, 31(5), 495-514. https://doi.org/10.1023/A:1025449031360

Carthy, T., Horesh, N., Apter, A., \& Gross, J. J. (2010). Patterns of emotional reactivity and regulation in children with anxiety disorders. Journal of Psychopathology and Behavioral Assessment, 32(1), 23-36. https://doi.org/10.1007/s10862-009-9167-8

Cassano, M. C., \& Zeman, J. L. (2010). Parental socialization of sadness regulation in middle childhood: The role of expectations and gender. Developmental Psychology, 46(5), 12141226. https://doi.org/10.1037/a0019851

Cassidy, J. (1994). Emotion regulation: Influences of attachment relationships. Monographs of the Society for Research in Child Development, 59(2-3), 228-249. https://doi.org/10.1111/j.1540-5834.1994.tb01287.x

Chaplin, T. M., Casey, J., Sinha, R., \& Mayes, L. C. (2010). Gender differences in caregiver emotion socialization of low-income toddlers. New Directions for Child and Adolescent Development, 2010(128), 11-27. https://doi.org/10.1002/cd.266

Chavira, D. A., Stein, M. B., Bailey, K., \& Stein, M. T. (2004a). Child anxiety in primary care: Prevalent but untreated. Depression and Anxiety, 20(4), 155-164. https://doi.org/10.1002/da.20039

Chavira, D. A., Stein, M. B., Bailey, K., \& Stein, M. T. (2004b). Comorbidity of generalized social anxiety disorder and depression in a pediatric primary care sample. Journal of Affective Disorders, 80(2-3), 163-171. https://doi.org/10.1016/S0165-0327(03)00103-4

Cisler, J. M., Olatunji, B. O., Feldner, M. T., \& Forsyth, J. P. (2010). Emotion regulation and the anxiety disorders: An integrative review. Journal of Psychopathology and Behavioral Assessment, 32(1), 68-82. https://doi.org/10.1007/s10862-009-9161-1

Cole, P. M., Dennis, T. A., Smith-Simon, K. E., \& Cohen, L. H. (2009). Preschoolers' emotion regulation strategy understanding: Relations with emotion socialization and child selfregulation. Social Development, 18(2), 324-352. https://doi.org/10.1111/j.14679507.2008.00503.x 
Cole, P. M., Martin, S. E., \& Dennis, T. A. (2004). Emotion regulation as a scientific construct: Methodological challenges and directions for child development research. Child Development, 75(2), 317-333. https://doi.org/https://doi.org/10.1111/j.14678624.2004.00673.x

Cooper, P. J., Fearn, V., Willetts, L., Seabrook, H., \& Parkinson, M. (2006). Affective disorder in the parents of a clinic sample of children with anxiety disorders. Journal of Affective Disorders, 93(1-3), 205-212. https://doi.org/10.1016/j.jad.2006.03.017

Costello, E. J., Mustillo, S., Erkanli, A., Keeler, G., \& Angold, A. (2003). Prevalence and development of psychiatric disorders in childhood and adolescence. Archives of General Psychiatry, 60(8), 837-844. https://doi.org/10.1001/archpsyc.60.8.837

Crockenberg, S. C., \& Leerkes, E. M. (2004). Infant and maternal behaviors regulate infant reactivity to novelty at 6 months. Developmental Psychology, 40(6), 1123-1132. https://doi.org/10.1037/0012-1649.40.6.1123

Dadds, M. R., Holland, D. E., Laurens, K. R., Mullins, M., Barrett, P. M., \& Spence, S. H. (1999). Early intervention and prevention of anxiety disorders in children: Results at 2-year follow-up. Journal of Consulting and Clinical Psychology, 67(1), 145-150. https://doi.org/10.1037/0022-006X.67.1.145

Dadds, M. R., \& Roth, J. (2001). Family processes in the development of anxiety problems. In M. Vasey \& M. Dadds (Eds.), The developmental psychopathology of anxiety (pp. 278303). New York: Oxford University Press.

Denham, S. A., Bassett, H. H., \& Wyatt, T. (2007). The socialization of emotional competence. In J. E. Grusec \& P. D. Hastings (Eds.), Handbook of socialization: Theory and research (pp. 614-637). New York: Guilford Press.

Diener, M. L., \& Mangelsdorf, S. C. (1999). Behavioral strategies for emotion regulation in toddlers: Associations with maternal involvement and emotional expressions. Infant Behavior and Development, 22(4), 569-583. https://doi.org/10.1016/S0163-6383(00)000126

Dunbar, A. S., Leerkes, E. M., Coard, S. I., Supple, A. J., \& Calkins, S. (2017). An integrative conceptual model of parental racial/ethnic and emotion socialization and links to children's social-emotional development among African American families. Child Development Perspectives, 11(1), 16-22. https://doi.org/10.1111/cdep.12218 
Duncan, L. G., Coatsworth, J. D., \& Greenberg, M. T. (2009). A model of mindful parenting: Implications for parent-child relationships and prevention research. Clinical Child and Family Psychology Review, 12(3), 255-270. https://doi.org/10.1007/s10567-009-0046-3

Durbin, C. E., Hayden, E. P., Klein, D. N., \& Olino, T. M. (2007). Stability of laboratoryassessed temperamental emotionality traits from ages 3 to 7 . Emotion, 7(2), 388-399. https://doi.org/10.1037/1528-3542.7.2.388

Edwards, S. L., Rapee, R. M., \& Kennedy, S. (2010). Prediction of anxiety symptoms in preschool-aged children: Examination of maternal and paternal perspectives. Journal of Child Psychology and Psychiatry, 51(3), 313-321. https://doi.org/10.1111/j.14697610.2009.02160.x

Ehrenreich-May, J., \& Bilek, E. L. (2012). The development of a transdiagnostic, cognitive behavioral group intervention for childhood anxiety disorders and co-occurring depression symptoms. Cognitive and Behavioral Practice, 19(1), 41-55. https://doi.org/10.1016/J.CBPRA.2011.02.003

Eisenberg, N., Cumberland, A., \& Spinrad, T. L. (1998). Parental socialization of emotion. Psychological Inquiry, 9(4), 241-273. https://doi.org/10.1207/s15327965pli0904_1

Eisenberg, N., Spinrad, T. L., Eggum, N. M., Silva, K. M., Reiser, M., Hofer, C., ... Michalik, N. (2010). Relations among maternal socialization, effortful control, and maladjustment in early childhood. Development and Psychopathology, 22(3), 507-525. https://doi.org/10.1017/S0954579410000246

Eisenberg, N., Valiente, C., Spinrad, T. L., Liew, J., Zhou, Q., Losoya, S. H., ... Cumberland, A. (2009). Longitudinal relations of children's effortful control, impulsivity, and negative emotionality to their externalizing, internalizing, and co-occurring behavior problems. Developmental Psychology, 45(4), 988-1008. https://doi.org/10.1037/a0016213

Enders, C. K., \& Bandalos, D. L. (2001). The relative performance of full information maximum likelihood estimation for missing data in structural equation models. Structural Equation Modeling: A Multidisciplinary Journal, 8(3), 430-457. https://doi.org/10.1207/s15328007sem0803_5

Engle, J. M., \& McElwain, N. L. (2011). Parental reactions to toddlers' negative emotions and child negative emotionality as correlates of problem behavior at the age of three. Social Development, 20(2), 251-271. https://doi.org/10.1111/j.1467-9507.2010.00583.x 
Fabes, R. A., Eisenberg, N., \& Bernzweig, J. (1990). The Coping with Children's Negative Emotions Scale: Procedures and scoring. Arizona State University.

Fabes, R. A., Leonard, S. A., Kupanoff, K., \& Martin, C. L. (2001). Parental coping with children's negative emotions: Relations with children's emotional and social responding. Child Development, 72(3), 907-920. https://doi.org/10.1111/1467-8624.00323

Fabes, R. A., Poulin, R., Eisenberg, N., \& Madden-Derdich, D. A. (2002). The Coping with Children's Negative Emotions Scale (CCNES): Psychometric properties and relations with children's emotional competence. Marriage \& Family Review, 34(3-4), 285-310. https://doi.org/10.1300/J002v34n03_05

Fendrich, M., Warner, V., \& Weissman, M. M. (1990). Family risk factors, parental depression, and psychopathology in offspring. Developmental Psychology, 26(1), 40-50. https://doi.org/10.1037/0012-1649.26.1.40

Folk, J. B., Zeman, J. L., Poon, J. A., \& Dallaire, D. H. (2014). A longitudinal examination of emotion regulation: Pathways to anxiety and depressive symptoms in urban minority youth. Child and Adolescent Mental Health, 19(4), 243-250. https://doi.org/10.1111/camh.12058

Franklin, J. C., Jamieson, J. P., Glenn, C. R., \& Nock, M. K. (2015). How developmental psychopathology theory and research can inform the research domain criteria (RDoC) project. Journal of Clinical Child \& Adolescent Psychology, 44(2), 280-290. https://doi.org/10.1080/15374416.2013.873981

Franz, L., Angold, A., Copeland, W., Costello, E. J., Towe-Goodman, N., \& Egger, H. (2013). Preschool anxiety disorders in pediatric primary care: Prevalence and comorbidity. Journal of the American Academy of Child \& Adolescent Psychiatry, 52(12), 1294-1303. https://doi.org/10.1016/J.JAAC.2013.09.008

Garside, R. B., \& Klimes-Dougan, B. (2002). Socialization of discrete negative emotions: Gender differences and links with psychological distress. Sex Roles, 47(3-4), 115-128. https://doi.org/10.1023/A:1021090904785

Goldsmith, H. H., Pollak, S. D., \& Davidson, R. J. (2008). Developmental neuroscience perspectives on emotion regulation. Child Development Perspectives, 2(3), 132-140. https://doi.org/10.1111/j.1750-8606.2008.00055.x

Goldsmith, H. H., Reilly, J., Lemery, K. S., Longley, S., \& Prescott, A. (2001). The Laboratory Temperament Assessment Battery: Middle Childhood Version. 
Goodman, S. H., Rouse, M. H., Connell, A. M., Broth, M. R., Hall, C. M., \& Heyward, D. (2011). Maternal depression and child psychopathology: A meta-analytic review. Clinical Child and Family Psychology Review, 14(1), 1-27. https://doi.org/10.1007/s10567-0100080-1

Graham, J. W. (2009). Missing data analysis: Making it work in the real world. Annual Review of Psychology, 60, 549-576. https://doi.org/10.1146/annurev.psych.58.110405.085530

Graham, J. W., Cumsille, P. E., \& Shevock, A. E. (2012). Methods for handling missing data. In I. B. Weiner, J. A. Schinka, \& W. F. Velicer (Eds.), Handbook of psychology, volume 2: Research methods in psychology. https://doi.org/10.1002/9781118133880.hop202004

Gratz, K. L., \& Roemer, L. (2004). Multidimensional assessment of emotion regulation and dysregulation: Development, factor structure, and initial validation of the Difficulties in Emotion Regulation Scale. Journal of Psychopathology and Behavioral Assessment, 26(1), 41-54. https://doi.org/10.1023/B:JOBA.0000007455.08539.94

Graziano, P. A., Calkins, S. D., \& Keane, S. P. (2011). Sustained attention development during the toddlerhood to preschool period: Associations with toddlers' emotion regulation strategies and maternal behaviour. Infant and Child Development, 20(6), 389-408. https://doi.org/10.1002/icd.731

Grolnick, W. S., Bridges, L. J., \& Connell, J. P. (1996). Emotion regulation in two-year-olds: Strategies and emotional expression in four contexts. Child Development, 67(3), 928-941. https://doi.org/10.1111/j.1467-8624.1996.tb01774.x

Gross, J. (2015). Parental responses to children's negative emotions: Relations with diverse forms of prosocial behavior in Head Start preschoolers (University of Maryland). https://doi.org/10.13016/M2MF0Q

Grüner, K., Muris, P., \& Merckelbach, H. (1999). The relationship between anxious rearing behaviours and anxiety disorders symptomatology in normal children. Journal of Behavior Therapy and Experimental Psychiatry, 30(1), 27-35. https://doi.org/10.1016/S00057916(99)00004-X

Gudmundson, J. A., \& Leerkes, E. M. (2012). Links between mothers' coping styles, toddler reactivity, and sensitivity to toddler's negative emotions. Infant Behavior and Development, 35(1), 158-166. https://doi.org/10.1016/J.INFBEH.2011.07.004

Han, Z. R., \& Shaffer, A. (2013). The relation of parental emotion dysregulation to children's 
psychopathology symptoms: The moderating role of child emotion dysregulation. Child Psychiatry \& Human Development, 44(5), 591-601. https://doi.org/10.1007/s10578-0120353-7

Havighurst, S., \& Kehoe, C. (2017). The role of parental emotion regulation in parent emotion socialization: Implications for intervention. In K. Deater-Deckard \& R. Panneton (Eds.), Parental Stress and Early Child Development: Adaptive and Maladaptive Outcomes (pp. 285-307). https://doi.org/10.1007/978-3-319-55376-4_12

Hayes, A. F. (2017). Introduction to mediation, moderation, and conditional process analysis: A regression-based approach (2nd ed.). New York: Guilford Press.

Hofmann, S. G., Sawyer, A. T., Fang, A., \& Asnaani, A. (2012). Emotion dysregulation model of mood and anxiety disorders. Depression and Anxiety, 29(5), 409-416. https://doi.org/10.1002/da.21888

Hooper, E. G., Wu, Q., Ku, S., Gerhardt, M., \& Feng, X. (2018). Maternal emotion socialization and child outcomes among African Americans and European Americans. Journal of Child and Family Studies, 27(6), 1870-1880. https://doi.org/10.1007/s10826-018-1020-9

Hu, L., \& Bentler, P. M. (1999). Cutoff criteria for fit indexes in covariance structure analysis: Conventional criteria versus new alternatives. Structural Equation Modeling: A Multidisciplinary Journal, 6(1), 1-55. https://doi.org/10.1080/10705519909540118

Hughes, E. K., \& Gullone, E. (2010a). Parent emotion socialisation practices and their associations with personality and emotion regulation. Personality and Individual Differences, 49(7), 694-699. https://doi.org/10.1016/J.PAID.2010.05.042

Hughes, E. K., \& Gullone, E. (2010b). Reciprocal relationships between parent and adolescent internalizing symptoms. Journal of Family Psychology, 24(2), 115-124. https://doi.org/10.1037/a0018788

Hurrell, K. E., Hudson, J. L., \& Schniering, C. A. (2015). Parental reactions to children's negative emotions: Relationships with emotion regulation in children with an anxiety disorder. Journal of Anxiety Disorders, 29(January), 72-82. https://doi.org/10.1016/J.JANXDIS.2014.10.008

In-Albon, T., Kossowsky, J., \& Schneider, S. (2010). Vigilance and avoidance of threat in the eye movements of children with separation anxiety disorder. Journal of Abnormal Child Psychology, 38, 225-235. https://doi.org/10.1007/s10802-009-9359-4 
Kiel, E. J., \& Kalomiris, A. E. (2015). Current themes in understanding children's emotion regulation as developing from within the parent-child relationship. Current Opinion in Psychology, 3, 11-16. https://doi.org/10.1016/J.COPSYC.2015.01.006

Kim, H. K., Pears, K. C., Capaldi, D. M., \& Owen, L. D. (2009). Emotion dysregulation in the intergenerational transmission of romantic relationship conflict. Journal of Family Psychology, 23(4), 585-595. https://doi.org/10.1037/a0015935

Klimes-Dougan, B., Brand, A. E., Zahn-Waxler, C., Usher, B., Hastings, P. D., Kendziora, K., \& Garside, R. B. (2007). Parental emotion socialization in adolescence: Differences in sex, age and problem status. Social Development, 16(2), 326-342.

https://doi.org/10.1111/j.1467-9507.2007.00387.x

Kline, R. B. (2011). Principles and Practice of Structural Equation Modeling (3rd ed.). New York: Guilford Press.

Kopp, C. B. (1989). Regulation of distress and negative emotions: A developmental view. Developmental Psychology, 25(3), 343-354. https://doi.org/10.1037/0012-1649.25.3.343

Leerkes, E. M., Parade, S. H., \& Gudmundson, J. A. (2011). Mothers' emotional reactions to crying pose risk for subsequent attachment insecurity. Journal of Family Psychology, 25(5), 635-643. https://doi.org/10.1037/a0023654

Lieb, R., Wittchen, H.-U., Höfler, M., Fuetsch, M., Stein, M. B., \& Merikangas, K. R. (2000). Parental psychopathology, parenting styles, and the risk of social phobia in offspring. Archives of General Psychiatry, 57(9), 859-866. https://doi.org/10.1001/archpsyc.57.9.859

Lougheed, J. P., \& Hollenstein, T. (2012). A limited repertoire of emotion regulation strategies is associated with internalizing problems in adolescence. Social Development, 21(4), 704-721. https://doi.org/10.1111/j.1467-9507.2012.00663.x

Luebbe, A., Kiel, E., \& Buss, K. (2011). Toddlers' context-varying emotions, maternal responses to emotions, and internalizing behaviors. Emotion, 11(3), 697-703. https://doi.org/10.1037/a0022994

Lunkenheimer, E. S., Shields, A. M., \& Cortina, K. S. (2007). Parental emotion coaching and dismissing in family interaction. Social Development, 16(2), 232-248. https://doi.org/10.1111/j.1467-9507.2007.00382.x

Malatesta, C. Z., \& Haviland, J. M. (1982). Learning display rules: The socialization of emotion expression in infancy. Child Development, 53(4), 991-1003. 
https://doi.org/10.2307/1129139

Maliken, A. C., \& Katz, L. F. (2013). Exploring the impact of parental psychopathology and emotion regulation on evidence-based parenting interventions: A transdiagnostic approach to improving treatment effectiveness. Clinical Child and Family Psychology Review, 16(2), 173-186. https://doi.org/10.1007/s10567-013-0132-4

Mangelsdorf, S. C., Shapiro, J. R., \& Marzolf, D. (1995). Developmental and temperamental differences in emotion regulation in infancy. Child Development, 66(6), 1817-1828. https://doi.org/10.1111/j.1467-8624.1995.tb00967.x

Mangold. (2017). INTERACT user guide. Retrieved from www.mangold-international.com Martini, J., Knappe, S., Beesdo-Baum, K., Lieb, R., \& Wittchen, H.-U. (2010). Anxiety disorders before birth and self-perceived distress during pregnancy: Associations with maternal depression and obstetric, neonatal and early childhood outcomes. Early Human Development, 86(5), 305-310. https://doi.org/10.1016/J.EARLHUMDEV.2010.04.004

McClure, E. B., Brennan, P. A., Hammen, C., \& Le Brocque, R. M. (2001). Parental anxiety disorders, child anxiety disorders, and the perceived parent-child relationship in an Australian high-risk sample. Journal of Abnormal Child Psychology, 29(1), 1-10. https://doi.org/10.1023/A:1005260311313

McLaughlin, K. A., Hatzenbuehler, M. L., Mennin, D. S., \& Nolen-Hoeksema, S. (2011). Emotion dysregulation and adolescent psychopathology: A prospective study. Behaviour Research and Therapy, 49(9), 544-554. https://doi.org/10.1016/j.brat.2011.06.003

Mcleod, B. D., Wood, J. J., \& Weisz, J. R. (2007). Examining the association between parenting and childhood anxiety: A meta-analysis. Clinical Psychology Review, 27(2), 155-172. https://doi.org/10.1016/j.cpr.2006.09.002

Mendlowitz, S. L., Manassis, K., Bradley, S., Scapillato, D., Miezitis, S., \& Shaw, B. F. (1999). Cognitive-behavioral group treatments in childhood anxiety disorders: The role of parental involvement. Journal of the American Academy of Child and Adolescent Psychiatry, 38(10), 1223-1229. https://doi.org/10.1097/00004583-199910000-00010

Mennin, D. S., Heimberg, R. G., Turk, C. L., \& Fresco, D. M. (2005). Preliminary evidence for an emotion dysregulation model of generalized anxiety disorder. Behaviour Research and Therapy, 43(10), 1281-1310. https://doi.org/10.1016/j.brat.2004.08.008

Merikangas, K. R., Dierker, L. C., \& Szatmari, P. (1998). Psychopathology among offspring of 
parents with substance abuse and/or anxiety disorders: A high-risk study. Journal of Child Psychology and Psychiatry and Allied Disciplines, 39(5), 711-720.

Mian, N. D., Wainwright, L., Briggs-Gowan, M. J., \& Carter, A. S. (2011). An ecological risk model for early childhood anxiety: The importance of early child symptoms and temperament. Journal of Abnormal Child Psychology, 39(4), 501-512. https://doi.org/10.1007/s10802-010-9476-0

Miller-Slough, R. L., \& Dunsmore, J. C. (2016). Parent and friend emotion socialization in adolescence: Associations with psychological adjustment. Adolescent Research Review, 1(4), 287-305. https://doi.org/10.1007/s40894-016-0026-Z

Miller, D. B., \& MacIntosh, R. (1999). Promoting resilience in urban African American adolescents: Racial socialization and identity as protective factors. Social Work Research, 23(3), 159-169.

Mirabile, S. P., Oertwig, D., \& Halberstadt, A. G. (2016). Parent emotion socialization and children's socioemotional adjustment: When is supportiveness no longer supportive? Social Development. https://doi.org/10.1111/sode.12226

Morelen, D., Shaffer, A., \& Suveg, C. (2016). Maternal emotion regulation: Links to emotion parenting and child emotion regulation. Journal of Family Issues, 37(13), 1-26. https://doi.org/10.1177/0192513X14546720

Morris, A. S., Houltberg, B. J., Criss, M. M., \& Bosler, C. D. (2017). Family context and psychopathology. In The Wiley Handbook of Developmental Psychopathology (pp. 365389). https://doi.org/10.1002/9781118554470.ch18

Morris, A. S., Silk, J. S., Steinberg, L., Myers, S. S., \& Robinson, L. R. (2007). The role of the family context in the development of emotion regulation. Social Development, 16(2), 361388. https://doi.org/10.1111/j.1467-9507.2007.00389.x

Muris, P., Meesters, C., Merckelbach, H., Sermon, A., \& Zwakhalen, S. (1998). Worry in normal children. Journal of the American Academy of Child \& Adolescent Psychiatry, 37(7), 703710. https://doi.org/10.1097/00004583-199807000-00009

Muris, P., \& Merckelbach, H. (1998). Perceived parental rearing behaviour and anxiety disorders symptoms in normal children. Personality and Individual Differences, 25(6), 1199-1206. https://doi.org/10.1016/S0191-8869(98)00153-6

Muris, P., van der Pennen, E., Sigmond, R., \& Mayer, B. (2008). Symptoms of anxiety, 
depression, and aggression in non-clinical children: Relationships with self-report and performance-based measures of attention and effortful control. Child Psychiatry and Human Development, 39(4), 455-467. https://doi.org/10.1007/s10578-008-0101-1

Murray, L., Creswell, C., \& Cooper, P. (2009). The development of anxiety disorders in childhood: An integrative review. Psychological Medicine, 39(9), 1413-1423. https://doi.org/10.1017/s0033291709005157

Muthén, L., \& Muthén, B. (2012). Mplus user's guide (7th ed.). Los Angeles.

Nachmias, M., Gunnar, M., Mangelsdorf, S., Parritz, R. H., \& Buss, K. (1996). Behavioral inhibition and stress reactivity: The moderating role of attachment security. Child Development, 67(2), 508-522. https://doi.org/10.1111/j.1467-8624.1996.tb01748.x

Neumann, A., van Lier, P. A. C., Gratz, K. L., \& Koot, H. M. (2010). Multidimensional assessment of emotion regulation difficulties in adolescents using the Difficulties in Emotion Regulation Scale. Assessment, 17(1), 138-149. https://doi.org/10.1177/1073191109349579

Nolen-Hoeksema, S., \& Watkins, E. R. (2011). A heuristic for developing transdiagnostic models of psychopathology: Explaining multifinality and divergent trajectories. Perspectives on Psychological Science, 6(6), 589-609. https://doi.org/10.1177/1745691611419672

O’Neal, C. R., \& Magai, C. (2005). Do parents respond in different ways when children feel different emotions? The emotional context of parenting. Development and Psychopathology, 17(2), 467-487. https://doi.org/10.1017/S0954579405050224

Ollendick, T. H., Grills, A. E., \& Alexander, K. L. (2001). Fears, worries, and anxiety in children and adolescents. In C. A. Essau \& F. Petermann (Eds.), Anxiety disorders in children and adolescents: Epidemiology, risk factors and treatment (pp. 1-36). New York: BrunnerRoutledge.

Ostlund, B. D., Vlisides-Henry, R. D., Crowell, S. E., Raby, K. L., Terrell, S., Brown, M. A., ... Conradt, E. (2019). Intergenerational transmission of emotion dysregulation: Part II. Developmental origins of newborn neurobehavior. Development and Psychopathology, 114. https://doi.org/10.1017/S0954579419000440

Perez Rivera, M. B., \& Dunsmore, J. C. (2011). Mothers' acculturation and beliefs about emotions, mother-child emotion discourse, and children's emotion understanding in Latino 
families. Early Education \& Development, 22(2), 324-354.

https://doi.org/10.1080/10409281003702000

Premo, J. E., \& Kiel, E. J. (2014). The effect of toddler emotion regulation on maternal emotion socialization: Moderation by toddler gender. Emotion, 14(4), 782-793. https://doi.org/10.1037/a0036684

Rapee, R. M., Kennedy, S. J., Ingram, M., Edwards, S. L., \& Sweeney, L. (2010). Altering the trajectory of anxiety in at-risk young children. American Journal of Psychiatry, 167(12), 1518-1525. https://doi.org/10.1176/appi.ajp.2010.09111619

Raval, V. V., Walker, B. L., \& Daga, S. S. (2018). Parental socialization of emotion and child functioning among Indian American families: Consideration of cultural factors and different modes of socialization. In S. Chuang \& C. Costigan (Eds.), Parental Roles and Relationships in Immigrant Families (pp. 69-89). https://doi.org/10.1007/978-3-319-71399$1 \_5$

Rogers, M. L., Halberstadt, A. G., Castro, V. L., Maccormack, J. K., \& Garrett-Peters, P. (2016). Maternal emotion socialization differentially predicts third-grade children's emotion regulation and lability. Emotion, 16(2), 280-291. https://doi.org/10.1037/emo0000142

Sanders, W., Zeman, J. L., Poon, J., \& Miller, R. (2015). Child regulation of negative emotions and depressive symptoms: The moderating role of parental emotion socialization. Journal of Child and Family Studies, 24(2), 402-415. https://doi.org/10.1007/s10826-013-9850-y

Schwartz, O. S., Sheeber, L. B., Dudgeon, P., \& Allen, N. B. (2012). Emotion socialization within the family environment and adolescent depression. Clinical Psychology Review, 32(6), 447-453. https://doi.org/10.1016/J.CPR.2012.05.002

Seligman, L. D., \& Ollendick, T. H. (1998). Comorbidity of anxiety and depression in children and adolescents: An integrative review. Clinical Child and Family Psychology Review, 1(2), 125-144. https://doi.org/10.1023/A:1021887712873

Shipman, K. L., Schneider, R., Fitzgerald, M. M., Sims, C., Swisher, L., \& Edwards, A. (2007). Maternal emotion socialization in maltreating and non-maltreating families: Implications for children's emotion regulation. Social Development, 16(2), 268-285. https://doi.org/10.1111/j.1467-9507.2007.00384.x

Shortt, A. L., Barrett, P. M., \& Fox, T. L. (2001). Evaluating the FRIENDS program: A cognitive-behavioral group treatment for anxious children and their parents. Journal of 
Clinical Child \& Adolescent Psychology, 30(4), 525-535.

https://doi.org/10.1207/S15374424JCCP3004_09

Shrout, P. E., \& Bolger, N. (2002). Mediation in experimental and nonexperimental studies: New procedures and recommendations. Psychological Methods, 7(4), 422-445.

https://doi.org/10.1037//1082-989X.7.4.422

Silva, E., Freire, T., \& Faria, S. (2018). The emotion regulation strategies of adolescents and their parents: An experience sampling study. Journal of Child and Family Studies, 27(6), 1774-1785. https://doi.org/10.1007/s10826-018-1015-6

Spence, S. H., Rapee, R., McDonald, C., \& Ingram, M. (2001). The structure of anxiety symptoms among preschoolers. Behaviour Research and Therapy, 39(11), 1293-1316. https://doi.org/10.1016/S0005-7967(00)00098-X

Spinrad, T. L., Eisenberg, N., Gaertner, B., Popp, T., Smith, C. L., Kupfer, A., ... Hofer, C. (2007). Relations of maternal socialization and toddlers' effortful control to children's adjustment and social competence. Developmental Psychology, 43(5), 1170-1186. https://doi.org/10.1037/0012-1649.43.5.1170

Spinrad, T. L., Eisenberg, N., Kupfer, A., Gaertner, B., \& Michalik, N. (2004). The Coping with Toddlers' Negative Emotions Scale. Poster Session Presented at the Biennial International Conference on Infant Studies. Chicago, Illinois.

Sroufe, L. A. (2009). The concept of development in developmental psychopathology. Child Development Perspectives, 3(3), 178-183. https://doi.org/10.1111/j.17508606.2009.00103.x

Sroufe, L. A., \& Rutter, M. (1984). The domain of developmental psychopathology. Child Development, 55(1), 17-29. https://doi.org/10.2307/1129832

Stifter, C. A., \& Braungart, J. M. (1995). The regulation of negative reactivity in infancy: Function and development. Developmental Psychology, 31(3), 448-455. https://doi.org/10.1037//0012-1649.31.3.448

Suveg, C., Morelen, D., Brewer, G. A., \& Thomassin, K. (2010). The emotion dysregulation model of anxiety: A preliminary path analytic examination. Journal of Anxiety Disorders, 24(8), 924-930. https://doi.org/10.1016/j.janxdis.2010.06.018

Suveg, C., Shaffer, A., Morelen, D., \& Thomassin, K. (2011). Links between maternal and child psychopathology symptoms: Mediation through child emotion regulation and moderation 
through maternal behavior. Child Psychiatry \& Human Development, 42(5), 507-520. https://doi.org/10.1007/s10578-011-0223-8

Suveg, C., Zeman, J., Flannery-Schroeder, E., \& Cassano, M. (2005). Emotion socialization in families of children with an anxiety disorder. Journal of Abnormal Child Psychology, 33(2), 145-155. https://doi.org/10.1007/s10802-005-1823-1

Suveg, C., \& Zeman, J. L. (2004). Emotion regulation in children with anxiety disorders. Journal of Clinical Child \& Adolescent Psychology, 33(4), 750-759. https://doi.org/10.1207/s15374424jccp3304_10

Tandon, M., Cardeli, E., \& Luby, J. (2009). Internalizing disorders in early childhood: A review of depressive and anxiety disorders. Child and Adolescent Psychiatric Clinics of North America, 18(3), 593-610. https://doi.org/10.1016/j.chc.2009.03.004

Tao, A., Zhou, Q., \& Wang, Y. (2010). Parental reactions to children's negative emotions: Prospective relations to Chinese children's psychological adjustment. Journal of Family Psychology, 24(2), 135-144.

Thompson, R. A. (1994). Emotion regulation: A theme in search of definition. Monographs of the Society for Research in Child Development, 59(2-3), 25-52. https://doi.org/10.1111/j.1540-5834.1994.tb01276.x

Thompson, R. A. (2001). Childhood anxiety disorders from the perspective of emotion regulation and attachment. In M. W. Vasey \& M. R. Dadds (Eds.), The developmental psychopathology of anxiety (pp. 160-182). New York: Oxford University Press.

Thompson, R. A. (2019). Emotion dysregulation: A theme in search of definition. Development and Psychopathology, 1-11. https://doi.org/10.1017/S0954579419000282

Thompson, R. A., \& Calkins, S. D. (1996). The double-edged sword: Emotional regulation for children at risk. Development and Psychopathology, 8(1), 163-182. https://doi.org/10.1017/S0954579400007021

Thompson, R. A., \& Goodvin, R. (2007). Taming the tempest in the teapot: Emotion regulation in toddlers. In C. A. Brownell \& C. B. Kopp (Eds.), Socioemotional development in the toddler years: Transitions and transformations (pp. 320-343). New York: Guilford Press.

Thompson, R. A., \& Meyer, S. (2007). Socialization of emotion regulation in the family. In J. Gross (Ed.), Handbook of emotion regulation (pp. 249-268). New York: Guilford Press. van der Bruggen, C. O., Stams, G. J. J. M., \& Bögels, S. M. (2008). Research review: The 
relation between child and parent anxiety and parental control: A meta-analytic review. Journal of Child Psychology and Psychiatry, 49(12), 1257-1269. https://doi.org/10.1111/j.1469-7610.2008.01898.x

Viana, A. G., Dixon, L. J., Stevens, E. N., \& Ebesutani, C. (2016). Parental emotion socialization strategies and their interaction with child interpretation biases among children with anxiety disorders. Cognitive Therapy and Research, 40(5), 717-731. https://doi.org/10.1007/s10608-016-9783-z

Warren, S. L., Umylny, P., Aron, E., \& Simmens, S. J. (2006). Toddler anxiety disorders: A pilot study. Journal of the American Academy of Child and Adolescent Psychiatry, 45(7), 859866. https://doi.org/10.1097/01.0000220852.94392.eb

Wilamowska, Z. A., Thompson-Hollands, J., Fairholme, C. P., Ellard, K. K., Farchione, T. J., \& Barlow, D. H. (2010). Conceptual background, development, and preliminary data from the unified protocol for transdiagnostic treatment of emotional disorders. Depression and Anxiety, 27(10), 882-890. https://doi.org/10.1002/da.20735

Williams, S. R., \& Woodruff-Borden, J. (2015). Parent emotion socialization practices and child self-regulation as predictors of child anxiety: The mediating role of cardiac variability. Child Psychiatry \& Human Development, 46(4), 512-522. https://doi.org/10.1007/s10578014-0492-0

Yan, J., Han, Z. R., \& Li, P. (2016). Intergenerational transmission of perceived bonding styles and paternal emotion socialization: Mediation through paternal emotion dysregulation. Journal of Child and Family Studies, 25(1), 165-175. https://doi.org/10.1007/s10826-0150199-2

Yap, M. B. H., Allen, N. B., \& Sheeber, L. (2007). Using an emotion regulation framework to understand the role of temperament and family processes in risk for adolescent depressive disorders. Clinical Child and Family Psychology Review, 10(2), 180-196. https://doi.org/10.1007/s10567-006-0014-0

Zahn-Waxler, C., Klimes-Dougan, B., \& Slattery, M. J. (2000). Internalizing problems of childhood and adolescence: Prospects, pitfalls, and progress in understanding the development of anxiety and depression. Development and Psychopathology, 12(3), 443466.

Zeman, J. L., Cassano, M., \& Adrian, M. C. (2013). Socialization influences on children's and 
adolescents' emotional self-regulation processes. In K. C. Barrett, N. A. Fox, G. A. Morgan, D. J. Fidler, \& L. A. Daunhauer (Eds.), Handbook of self-regulatory processes in development: New directions and international perspectives (pp. 79-107). New York: Routledge.

Zeman, J. L., Shipman, K., \& Suveg, C. (2002). Anger and sadness regulation: Predictions to internalizing and externalizing symptoms in children. Journal of Clinical Child \& Adolescent Psychology, 31(3), 393-398. https://doi.org/10.1207/S15374424JCCP3103_11 


\section{Appendices}

Table 1

Descriptive Statistics of Primary Variables

Variable

n Mean SD Range

T1 maternal emotion dysregulation (DERS)

137

1.81

0.49

$1-3.39$

T2 maternal supportive responses (CTNES)

$\begin{array}{llll}110 & 5.48 & 0.88 & 1.93-6.97\end{array}$

T2 maternal unsupportive responses (CTNES)

$\begin{array}{llll}110 & 2.61 & 0.76 & 1.22-4.50\end{array}$

T2 observed distress across episodes

12

21

$1.57 \quad 0.71 \quad 1.00-3.50$

T2 observed caregiver-focused frequencies across

124

$17.73 \quad 10.56$

$3.00-86.00$ episodes (LabTAB)

T2 observed proportion of caregiver-focused

124

$9.00 \%$

$8.12 \%$

$0.4-49.8 \%$

emotion regulation across episodes (LabTAB)

T2 observed attention-focused frequencies across

124

8.40

6.08

$0.00-32.00$ episodes (LabTAB)

T2 observed proportion of attention-focused

$124 \quad 5.40 \%$

$5.11 \%$

$0-30.6 \%$

emotion regulation across episodes (LabTAB)

T3 child anxiety/worry (ITSEA)

94

$\begin{array}{lll}0.32 & 0.33 \quad 0.00-1.43\end{array}$

T3 child inhibition to novelty (ITSEA)

94
0.85
0.55
$0.00-2.00$

T3 child generalized anxiety (PAS)

84

$0.48 \quad 0.58 \quad 0.00-3.00$

T3 child social anxiety (PAS)

84

0.73

0.71

$0.00-3.83$

Note. All statistics were calculated prior to transformations, standardizations, and handling missing data. The range shown is the observed range; see Methods for full scale ranges. $\mathrm{T} 1=$ Time 1, T2 = Time 2, T3 = Time 3. Percentages of observed emotion regulation represent the proportion of time in which children were engaging in those behaviors, relative to the amount of observable seconds. 
Table 2

Correlations among Primary Variables

\begin{tabular}{|c|c|c|c|c|c|c|c|c|c|c|c|c|}
\hline Variable & 1 & 2 & 3 & 4 & 5 & 6 & 7 & 8 & 9 & 10 & 11 & 12 \\
\hline 1. Child sex & - & $.15^{\mathrm{t}}$ & .12 & .07 & .08 & .01 & .003 & -.03 & -.12 & -.04 & -.15 & -.10 \\
\hline 2. Family socioeconomic status & & - & .09 & .03 & .02 & -.09 & .01 & -.03 & .001 & $.27^{* *}$ & .04 & $.21^{\mathrm{t}}$ \\
\hline 3. T1 maternal emotion dysregulation & & & - & -.03 & $.36^{* *}$ & -.03 & -.11 & $.22^{*}$ & $.23^{\mathrm{t}}$ & .10 & $.29^{*}$ & $.28^{*}$ \\
\hline 4. T2 maternal supportive responses & & & & - & .02 & $.19^{\mathrm{t}}$ & .12 & .03 & .06 & .08 & .001 & -.07 \\
\hline 5. T2 maternal unsupportive responses & & & & & - & -.03 & .14 & $.16^{\mathrm{t}}$ & .03 & .04 & .15 & .17 \\
\hline 6. T2 child episode distress & & & & & & - & .14 & .009 & .07 & .17 & .14 & .06 \\
\hline 7. T2 child caregiver-focused regulation & & & & & & & - & .08 & -.12 & .02 & -.10 & -.08 \\
\hline 8. T2 child attention-focused regulation & & & & & & & & - & -.05 & .14 & $.21^{\mathrm{t}}$ & .16 \\
\hline 9. T3 child ITSEA anxiety/worry & & & & & & & & & - & $.40^{* * *}$ & $.68^{* * *}$ & $.53^{* * *}$ \\
\hline 10. T3 child ITSEA inhibition to novelty & & & & & & & & & & - & $.26^{*}$ & $.68^{* * *}$ \\
\hline 11. T3 child PAS generalized anxiety & & & & & & & & & & & - & $.56^{* * *}$ \\
\hline 12. T3 child PAS social anxiety & & & & & & & & & & & & - \\
\hline
\end{tabular}

Note. Correlations were computed after variable transformations with available data but prior to handling missing data. $N \mathrm{~s}$ for correlations ranged from 63 to $175 . \mathrm{T} 1=$ Time $1, \mathrm{~T} 2=$ Time $2, \mathrm{~T} 3=$ Time $3 .^{\dagger} p<.10,{ }^{*} p<.05, * * p<.01, * * * p<.001$. 


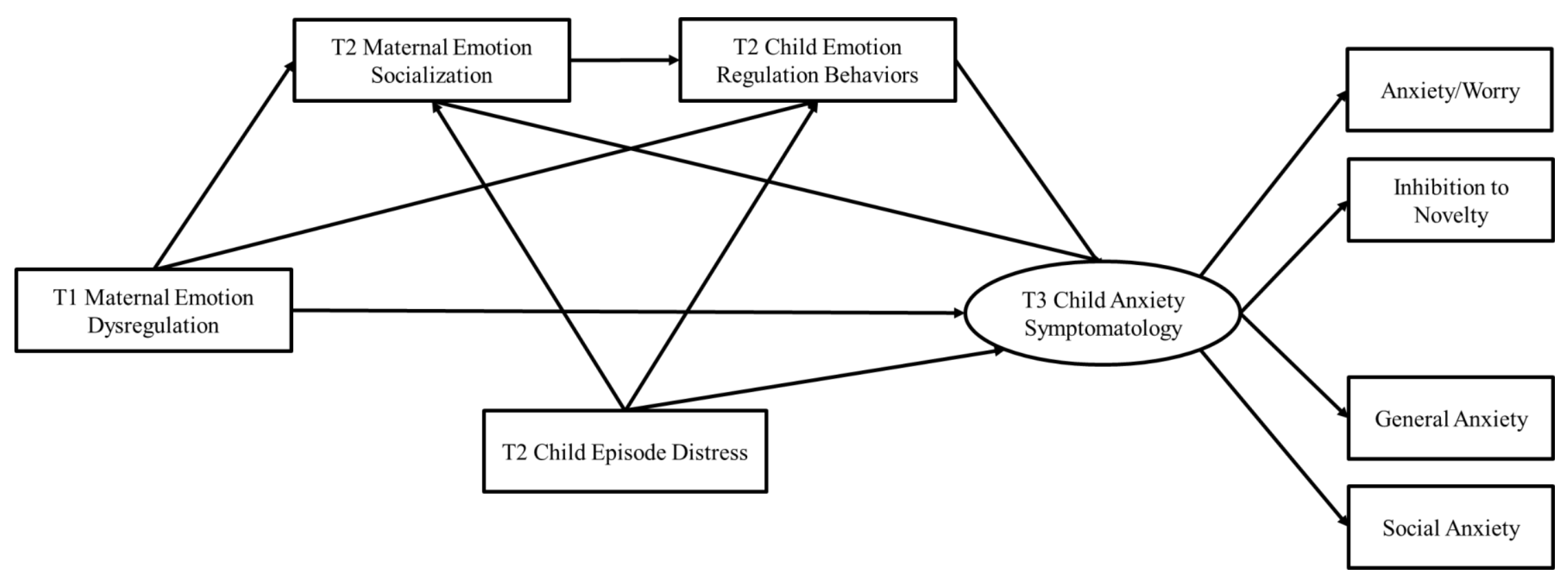

Figure 1. Conceptual model of structural equation models tested. Models varied on T2 maternal emotion socialization (i.e., supportive or unsupportive emotion socialization) and $\mathrm{T} 2$ child emotion regulation behavior (i.e., caregiver-focused or attention-focused regulation). The latent construct of $\mathrm{T} 3$ child anxiety was tested for adequate fit prior to incorporating into the larger model. $\mathrm{T} 1=\mathrm{Time}$ $1, \mathrm{~T} 2=$ Time $2, \mathrm{~T} 3=$ Time 3. 


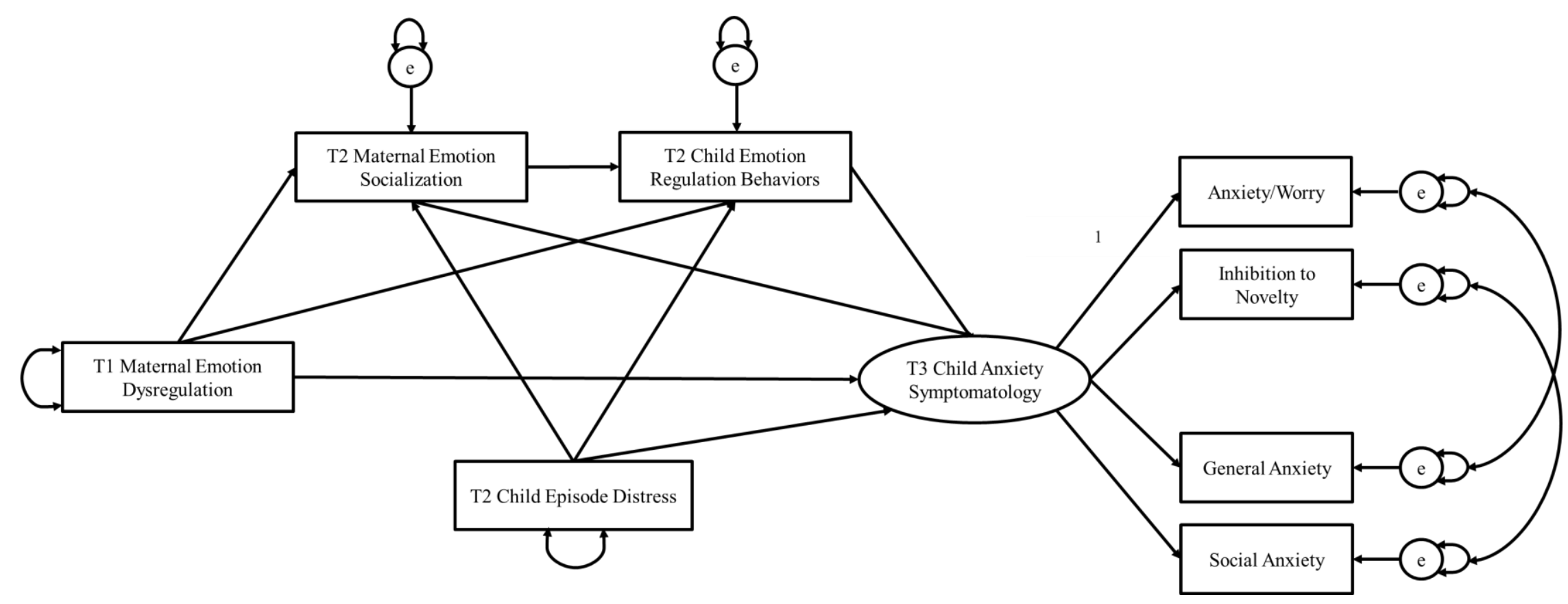

Figure 1. Conceptual model of structural equation models tested, with variances and error terms. The path between the manifest variable of ITSEA anxiety/worry and the latent construct of child anxiety was constrained to 1.00 . $\mathrm{T} 1=$ Time $1, \mathrm{~T} 2=\mathrm{Time} 2, \mathrm{~T} 3=$ Time 3. 


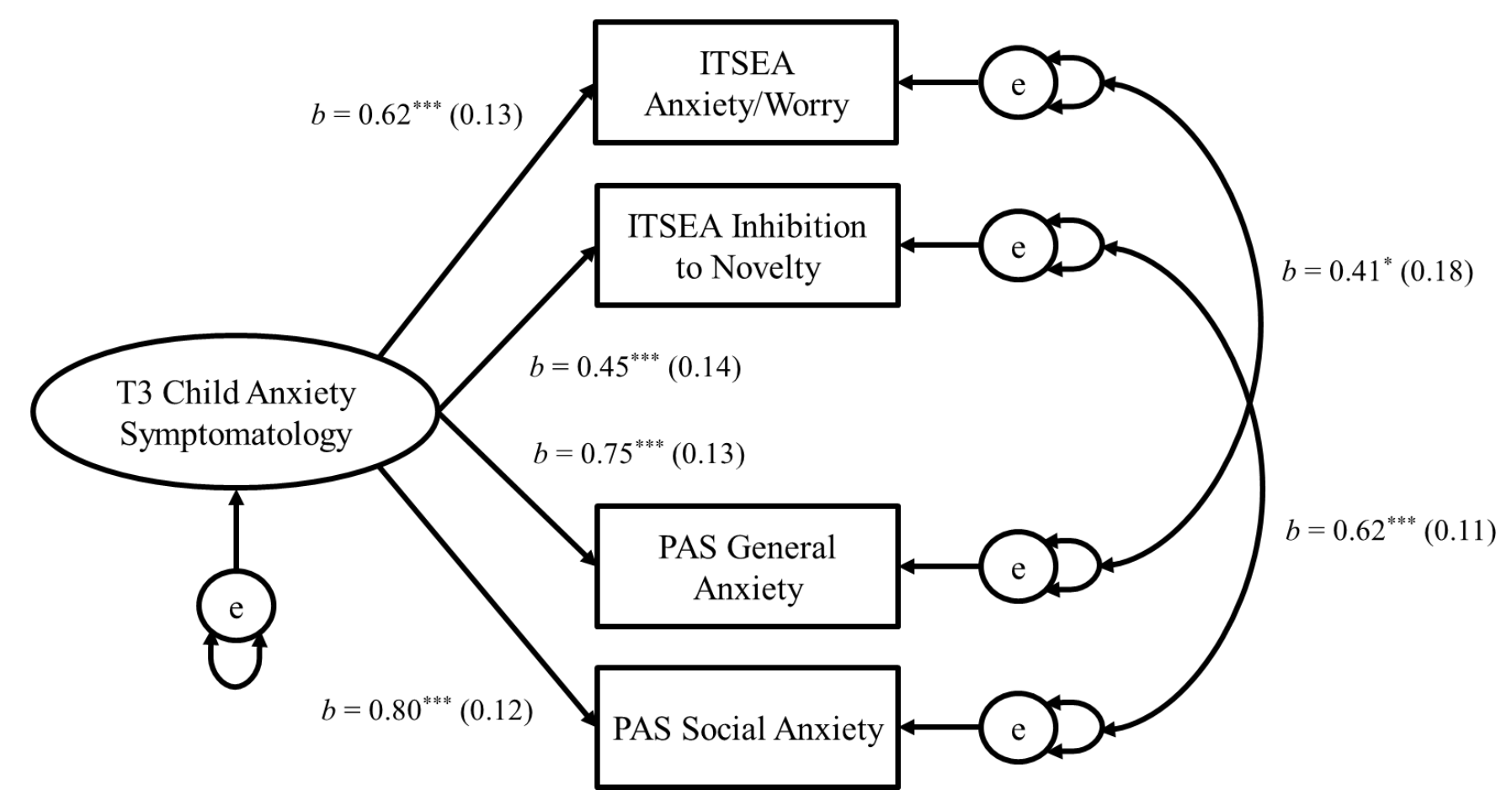

Figure 3. Measurement model of latent construct of T3 child anxiety symptoms, with variances and error terms. Standardized path coefficients are shown with standard error estimates in parentheses. The path between the manifest variable of ITSEA anxiety/worry and the latent construct of child anxiety was constrained to 1.00 in the larger structural equation model. T3 $=$ Time $3 .{ }^{t} p \leq .10,{ }^{*} p \leq$ $.05, * * p \leq .01, * * * p \leq .001$. 


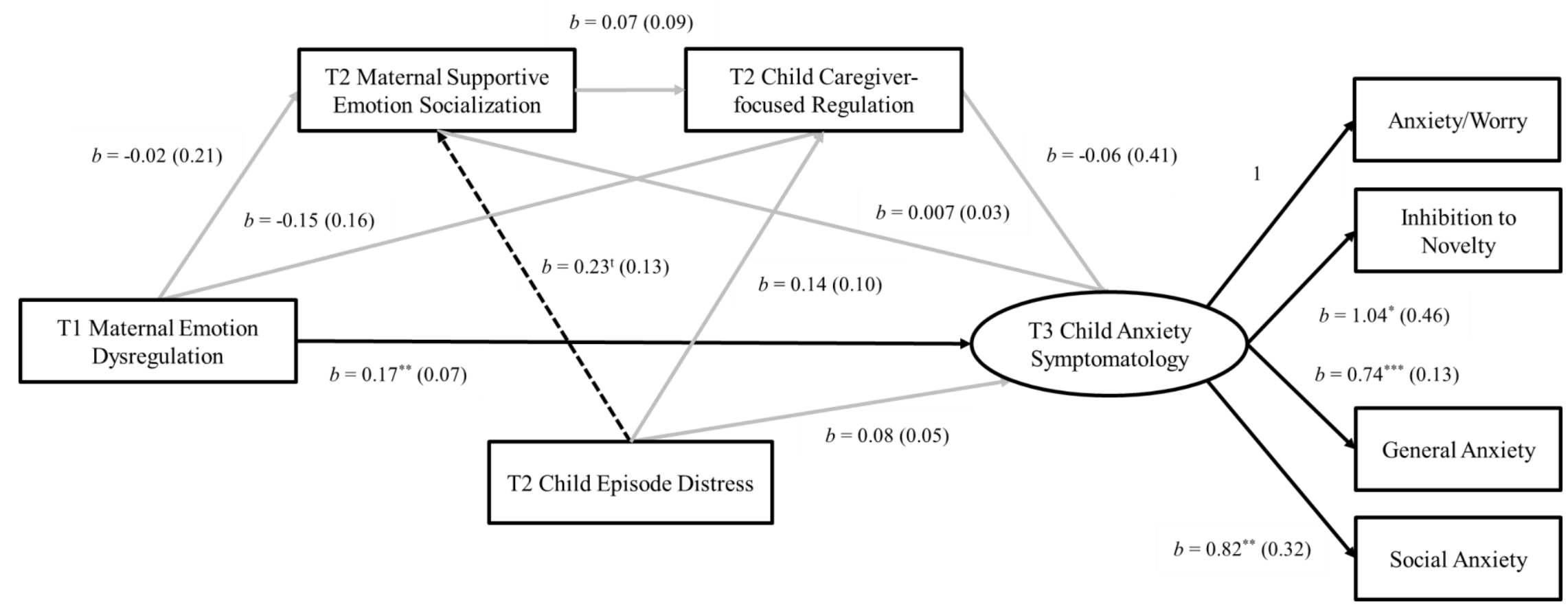

Figure 4. Structural equation model with supportive emotion socialization and caregiver-focused emotion regulation. Variances and error terms are omitted for ease of presentation. Unstandardized path coefficients are shown with standard error estimates in parentheses. Gray lines represent non-significant paths, dashed lines represent marginally significant paths, and solid black lines represent statistically significant paths. $\mathrm{T} 1=$ Time $1, \mathrm{~T} 2=$ Time $2, \mathrm{~T} 3=$ Time $3 .{ }^{t} p \leq .10,{ }^{*} p \leq .05,{ }^{* *} p \leq .01,{ }^{* * *} p \leq .001$. 


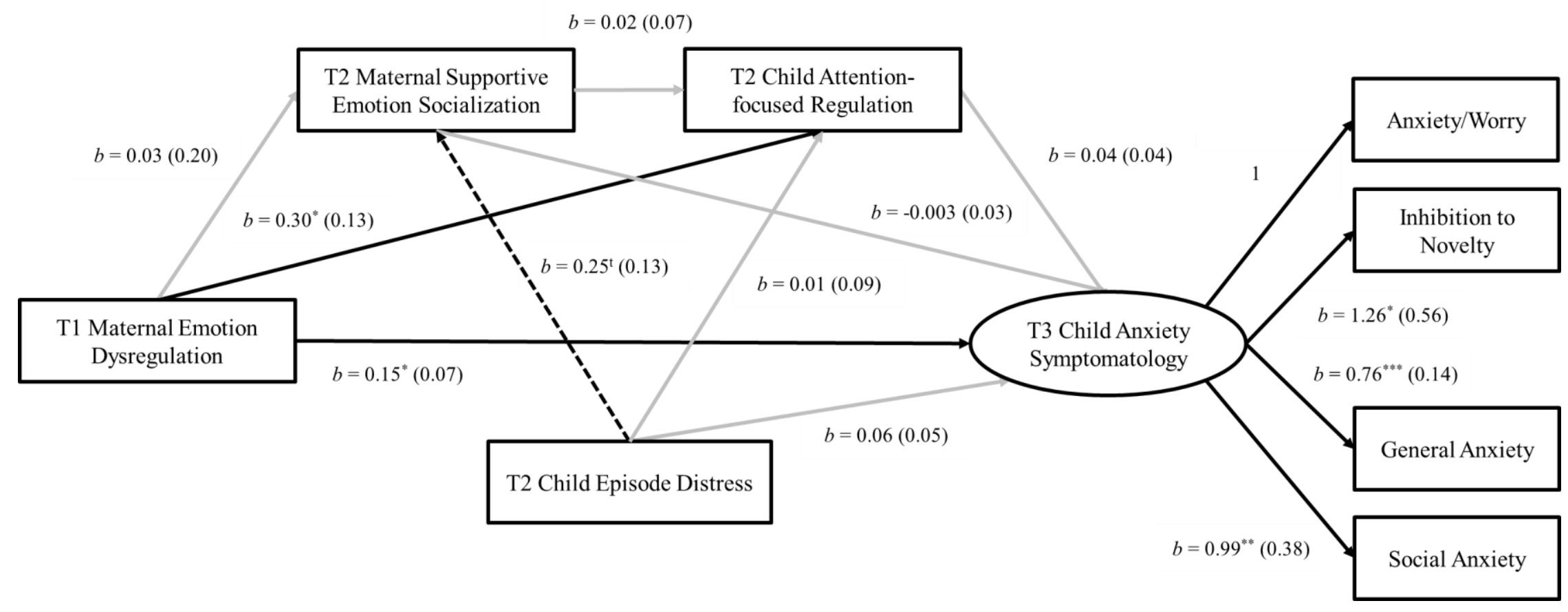

Figure 5. Structural equation model with supportive emotion socialization and attention-focused emotion regulation. Variances and error terms are omitted for ease of presentation. Unstandardized path coefficients are shown with standard error estimates in parentheses. Gray lines represent non-significant paths, dashed lines represent marginally significant paths, and solid black lines represent statistically significant paths. $\mathrm{T} 1=$ Time $1, \mathrm{~T} 2=$ Time $2, \mathrm{~T} 3=$ Time $3 .{ }^{t} p \leq .10,{ }^{*} p \leq .05,{ }^{* *} p \leq .01,{ }^{* * *} p \leq .001$. 


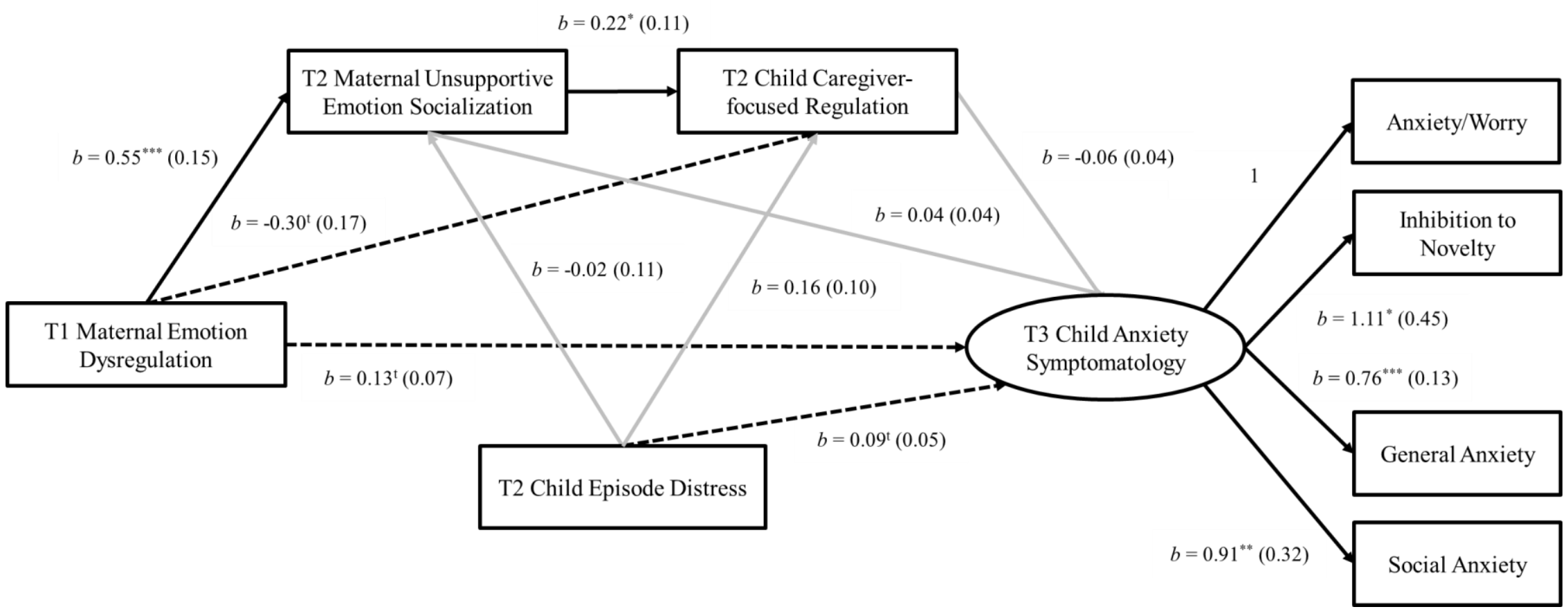

Figure 6. Structural equation model with unsupportive emotion socialization and caregiver-focused emotion regulation. Variances and error terms are omitted for ease of presentation. Unstandardized path coefficients are shown with standard error estimates in parentheses. Gray lines represent non-significant paths, dashed lines represent marginally significant paths, and solid black lines represent statistically significant paths. $\mathrm{T} 1=$ Time $1, \mathrm{~T} 2=$ Time $2, \mathrm{~T} 3=$ Time $3 .{ }^{t} p \leq .10,{ }^{*} p \leq .05,{ }^{* *} p \leq .01,{ }^{* * *} p \leq .001$. 


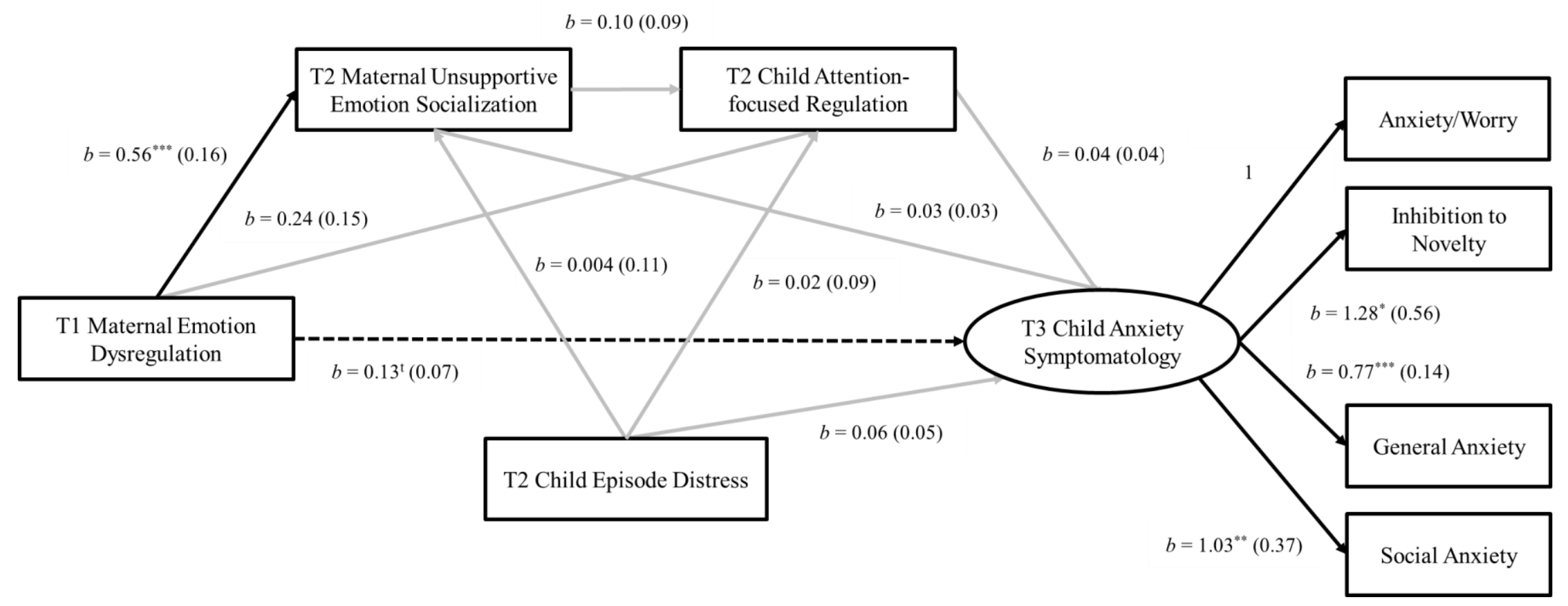

Figure 7. Structural equation model with unsupportive emotion socialization and attention-focused emotion regulation. Variances and error terms are omitted for ease of presentation. Unstandardized path coefficients are shown with standard error estimates in parentheses. Gray lines represent non-significant paths, dashed lines represent marginally significant paths, and solid black lines represent statistically significant paths. $\mathrm{T} 1=$ Time $1, \mathrm{~T} 2=$ Time $2, \mathrm{~T} 3=$ Time $3 .{ }^{t} p \leq .10,{ }^{*} p \leq .05,{ }^{* *} p \leq .01,{ }^{* * *} p \leq .001$. 


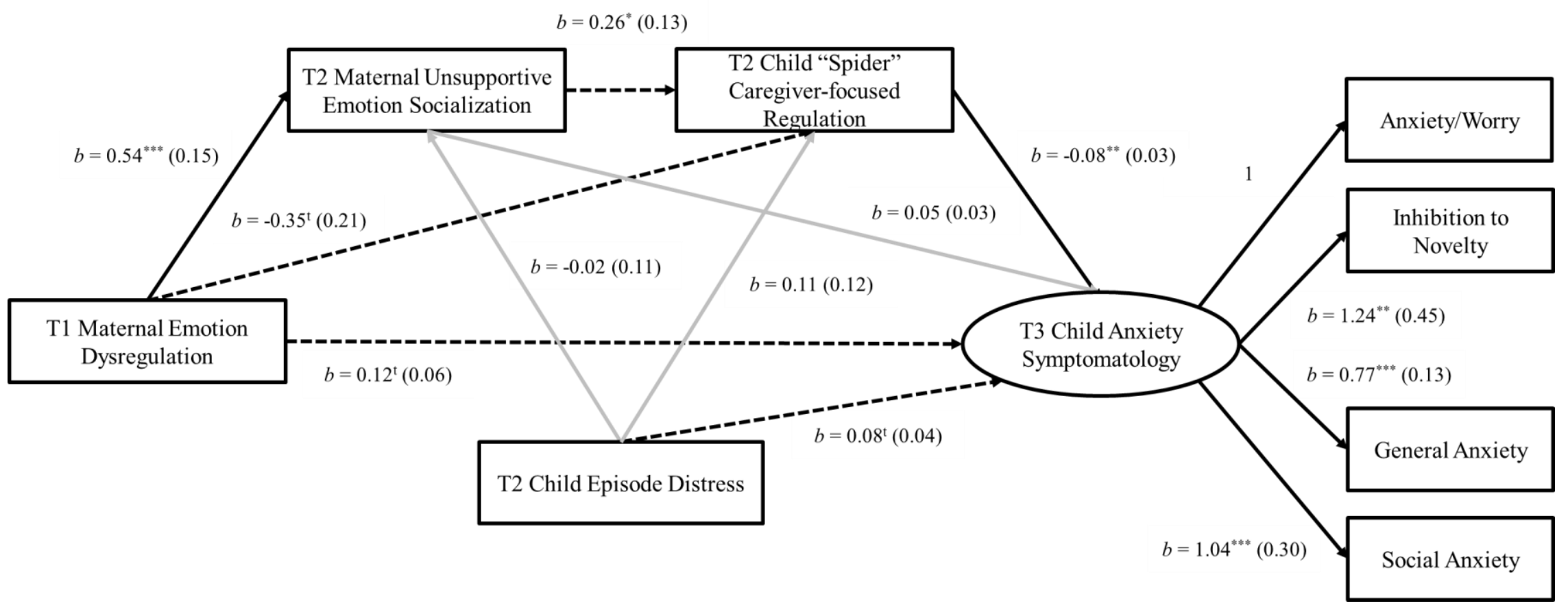

Figure 8. Structural equation model with unsupportive emotion socialization and caregiver-focused emotion regulation in the "spider" context only. Variances and error terms are omitted for ease of presentation. Unstandardized path coefficients are shown with standard error estimates in parentheses. Gray lines represent non-significant paths, dashed lines represent marginally significant paths, and solid black lines represent statistically significant paths. $\mathrm{T} 1=$ Time $1, \mathrm{~T} 2=$ Time $2, \mathrm{~T} 3=$ Time $3 .{ }^{t} p \leq .10,{ }^{*} p \leq .05,{ }^{* *} p \leq .01,{ }^{* * *} p \leq .001$. 